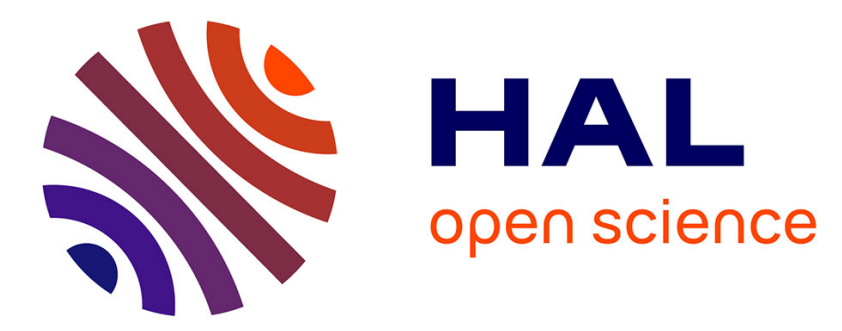

\title{
Pore-Scale Imaging and Modelling of Reactive Flow in Evolving Porous Media: Tracking the Dynamics of the Fluid-Rock Interface
}

Catherine Noiriel, Cyprien Soulaine

\section{- To cite this version:}

Catherine Noiriel, Cyprien Soulaine. Pore-Scale Imaging and Modelling of Reactive Flow in Evolving Porous Media: Tracking the Dynamics of the Fluid-Rock Interface. Transport in Porous Media, 2021, 140 (181-213), 10.1007/s11242-021-01613-2 . insu-03238325

HAL Id: insu-03238325

https://hal-insu.archives-ouvertes.fr/insu-03238325

Submitted on 21 Sep 2021

HAL is a multi-disciplinary open access archive for the deposit and dissemination of scientific research documents, whether they are published or not. The documents may come from teaching and research institutions in France or abroad, or from public or private research centers.
L'archive ouverte pluridisciplinaire $\mathbf{H A L}$, est destinée au dépôt et à la diffusion de documents scientifiques de niveau recherche, publiés ou non, émanant des établissements d'enseignement et de recherche français ou étrangers, des laboratoires publics ou privés. 


\title{
Pore-scale imaging and modelling of reactive flow in evolving porous media: tracking the dynamics of the fluid-rock interface
}

\author{
Catherine Noiriel · Cyprien Soulaine
}

Received: date / Accepted: date

\begin{abstract}
Fluid-mineral and fluid-rock interfaces are key parameters controlling the reactivity and fate of fluids in reservoir rocks and aquifers. The interface dynamics through space and time results from complex processes involving a tight coupling between chemical reactions and transport of species as well as a strong dependence on the physical, chemical, mineralogical and structural properties of the reacting solid phases. In this article, we review the recent advances in pore-scale imaging and reactive flow modelling applied to interface dynamics. Digital rocks derived from time-lapse X-ray micro-tomography imaging gives unprecedented opportunity to track the interface evolution during reactive flow experiments in porous or fractured media, and evaluate locally mineral reactivity. The recent improvements in porescale reactive transport modelling allow for a fine description of flow and transport that integrates moving fluid-mineral interfaces inherent to chemical reactions. Combined with three-dimensional digital images, pore-scale reactive transport modelling complements and augments laboratory experiments. The most advanced multi-scale models integrate sub-voxel porosity and processes which relate to imaging instrument resolution and improve upscaling possibilities. Two example applications based on the solver porousMedia4Foam illustrate the dynamics of the interface for different transport regimes (i.e., diffusive- to advective-dominant) and rock matrix properties (i.e., permeable versus impermeable, and homogeneous versus polymineralic). These parameters affect both the interface roughness and its geometry evolution, from sharp front to smeared (i.e., diffuse) interface. The paper concludes by discussing the challenges associated with precipitation processes in porous media, rock texture and composition (i.e., physical and mineralogical heterogeneity), and upscaling to larger scales.
\end{abstract}

Catherine Noiriel

Géosciences Environnement Toulouse, Observatoire Midi-Pyrénées, Université Paul Sabatier, CNRS, IRD, Université de Toulouse

14 avenue Edouard Belin, F-31400 Toulouse, France

E-mail: catherine.noiriel@univ-tlse3.fr

Cyprien Soulaine

Earth Sciences Institute of Orléans, Univ. Orléans, CNRS, BRGM, Orléans, France

1A rue de la Ferollerie, F-45071 Orléans

E-mail: cyprien.soulaine@cnrs-orleans.fr 
Keywords reactive flow $\cdot$ mineral reactivity $\cdot$ X-ray micro-tomography $\cdot$ digital rock physics · fluid-mineral interface - fluid-rock interface - carbonate dissolution · pore-scale imaging $\cdot$ pore-scale modelling $\cdot$ Darcy-Brinkman model

\section{Introduction}

Advances in high-resolution imaging techniques coupled with increasing computing power have enabled the emergence of pore-scale studies. This constitutes a major advance in the field of flow and transport in porous media over the last 20 years. The pore scale is an indispensable scale of observation to bridge the gap between the microscopic scale at which physico-chemical processes are finely described, and the chemically and physically heterogeneous reservoir scale that deals with averaged behaviours. An accurate prediction of reactive fluid flow and transport through time is required to assess the long-term performance of geo-engineering applications including $\mathrm{CO}_{2}$ sequestration, in situ leaching, hydrocarbon production, geothermal energy production, or nuclear waste, energy or $\mathrm{H}_{2}$ storage.

Traditional workflows for studying flow and transport in geological reservoirs rely on the continuum description of properties at the Darcy scale. At this scale, the representative elementary volume (REV) defines the minimum size of the domain over which measurement of a property stops oscillating and remains stable over a certain length-scale [18], and becomes a representative property of the considered domain. Such representative properties include porosity, permeability, dispersivity, or specific surface area. The presence of geochemical reactions that affect locally the rock microstructure, however, questions the concept of REV over time. For example, it is now well-established that permeability-porosity relationships such as KozenyCarman law do not capture accurately the modification of the microstructure because geochemical processes occur non-uniformly within the rock and depend on many parameters including transport regime and rock texture [102]. Pore-scale imaging and modelling, with typical length-scale ranging from a few nanometers to centimeters, offer unprecedentedo pportunities for predicting macroscopic properties of reservoir rocks $[49,104]$. Among 3D imaging techniques, X-ray micro-tomography (XMT) is now an essential tool for observation of the evolution of the microstructures with geochemical and reactive transport processes. The combination of high-resolution 3D images with direct numerical simulations, an emergent technology referred to as digital rock physics $[9,10,20]$, complements and augments the pore-scale observations.

The pore-scale simulators using 3D digital rocks have improved considerably since the pioneering work of Spanne et al. [138], and the determination of the permeability tensor is now achieved routinely by solving the Navier-Stokes equations in the pore space. The consideration of transport of multi-species or heterogeneous reactivity at the fluid-mineral interface, however, is more challenging. In particular, obstacles still remain to describe the transport of charged species [147], surface kinetics involving possible effect of catalyst or inhibitor species, or simply the specific surface area [102]. In addition, rocks are made of an assemblage of minerals and exhibit heterogeneous reactivity. This non-uniform reactivity at the solid surface degrades the REV representation through time because mass transfer associated with volume variations in the solid and fluid phases leads to a motion of the fluid-mineral interface. Obtaining continuum-scale relationships for effective transport properties and reactivity in 
porous media, under dynamically evolving conditions, constitutes a major challenge in the field [128].

This article focuses on the applications of high-resolution X-ray micro-tomography imaging and pore-scale reactive transport modelling to study the fluid-solid interface dynamics. The dynamics results from the complex interplay between geochemical reactions, flow and transport processes. In Section 2, we give an overview of image processing tools used to identify and characterize the fluid-solid interface from 3D imaging. In particular, we discuss the ability of XMT imaging to track the interface evolution and measure local reaction rates for different types of interfaces, including sharp and smeared (i.e., diffuse) interfaces. In Section 3, we introduce the governing equations at the pore-scale and the common computational strategies to move the fluid-mineral and fluid-rock interfaces. Then, in section 4 , we present two applications of interface evolution in different contexts that highlight the influence of surface reactions, species transport, and rock texture on the evolution of the interface retreat, structure, and roughness through time. Finally, in section 5, we discuss precipitation processes, mineral and structural rock heterogeneities, and upscaling, three technical and conceptual challenges for the future of reactive transport modelling.

\section{X-ray micro-tomography imaging as a tool to track temporal and spatial evolution of the geometry}

\subsection{Resolving pores from X-ray micro-tomography}

XMT relies on the three-dimensional (3D) reconstruction of a sample from a series of radiographs taken over $180^{\circ}$ or $360^{\circ}$ angular displacements. The technique is based on the measurement of the attenuation of an X-ray beam of photon energy E passing through a material over a distance $\varphi$ following the Beer-Lambert law:

$$
I=I_{0} \exp \left(\mu_{T i(E)} \times \varphi\right)
$$

with $\mu_{T i(E)}$ the linear attenuation coefficient of material $i$, and $I_{0}$ and $I$ the incident and transmitted beam intensity, respectively. Attenuation coefficients are additive over length. Therefore, a composite material crossed by an X-ray beam results in an average attenuation coefficient, $\bar{\mu}_{T(E)}$ :

$$
\bar{\mu}_{T(E)}=\int_{0}^{\varphi} \mu_{T i(E)} d \varphi .
$$

Materials with high attenuation coefficients absorb X-rays more efficiently than materials with low attenuation coefficients, thus resulting in brighter voxel intensity in the images.

The technique has become a readily available tool over the past 15 years for the three-dimensional imaging of a wide range of materials since the multiplication of lab-based systems including commercial desktop scanners and custom-made devices, in addition to synchrotron-based systems. These devices allow for routinely imaging samples with a spatial scale ranging from sub-millimeter to a decimeter in a couple of minutes or hours with a pixel size (or resolution) generally $\sim 1 / 2000$ of the sample size $[84,89]$. The resolution can be increased thanks to local tomography technique or multi-scan acquisitions. In the first case, the sample is larger than the field of 
view of the detector, so that specific reconstruction methods are required to account for the external parts of the sample which are not captured for each rotation. In the second case, the detector displacement results in a larger field of view and the set of radiographs taken at a given rotation stage are tiled before reconstruction $[63,89]$.

Reconstruction of $3 \mathrm{D}$ volumes from the set of radiographs provides a matrix of $N_{x} \times N_{y} \times N_{z}$ voxels. Each voxel takes a gray intensity proportional to the X-ray absorption by the different materials forming the sample, $\bar{\mu}_{T(E)}$.

One of the great advantage of XMT over several other characterisation techniques is that XMT is non-invasive and non-destructive. Some setup offer in situ imaging under experimental conditions in real time. They can be used to follow the four-dimensional (4D), time-lapse changes of geometry and fluid distribution during dynamic processes or experiments. Applications include multi-phase flow studies [23, $13,65]$, deformation experiments $[29,125,124]$ or hydro-geochemical processes [161, $50,28,91,88,104,81,82,57,105,100,103,1,51,22,82,43,74,39,151,4,91]$.

2.2 Tracking the dynamics of fluid-mineral and fluid-rock interfaces

Interface definition and propagation. Fluid-mineral and fluid-rock interfaces are examples of boundary surfaces separating two phases in contact, namely fluid and solid. They are key elements in surface reactivity. Their geometry can be flat or curved, sharp (i.e., well defined) or smeared (i.e., diffuse). Under reactive conditions, fluidmineral interfaces evolve with geochemical processes that occur at the solid surface [102]. The dynamic of reactive interfaces depends on a complex interplay between transport and surface reactions. Tracking the interface displacement is complex from a theoretical, mathematical, and technical point of view [129]. Most of the imaging and modelling challenges consist in describing adequately the interface in an Eulerian grid and the rate function that drives its displacement through time in a normal direction. The wide range of techniques that exist for defining interfaces in images or computational grids underlines this complexity (Figure 1). The interface geometry and topology evolve in a complex manner due to roughness alteration, the formation of microporous networks at the solid surface, or the passivation by newly formed phases [34]. Appropriate approaches for describing interfaces and their motion are therefore critically geometry- and resolution-dependent. We present methods to extract and represent the interface displacement from XMT imaging in relation to their geometry, i.e., flat, curved or smeared. Determination of the retreat from projections of the surface topography onto a $2 \mathrm{D}$ horizontal grid is quite accurate and easy to handle for flat interfaces, but the method has a limited scope for rough surfaces or curved interface geometries. Sharp and complex interface geometries require a full $3 \mathrm{D}$ representation derived from meshing or mapping of the distance transform after segmentation of the fluid/solid phases. In contrast, we derive properties of smeared interfaces, which are poorly-defined, from grayscale data sets.

Identification of sharp fluid-solid interfaces. Digitization of the pore space is a crucial step for performing direct numerical simulations of flow and transport in the digital representation of the rock sample [97,9]. When the resolution is high enough to resolve the interfaces, solid-phase and fluid-phase distributions can be retrieved from image segmentation. Segmentation consists in classifying and labeling voxels into two (e.g., air and rock matrix) or more discrete phases (e.g., fluid $i$, fluid $j$, mineral $i$, 

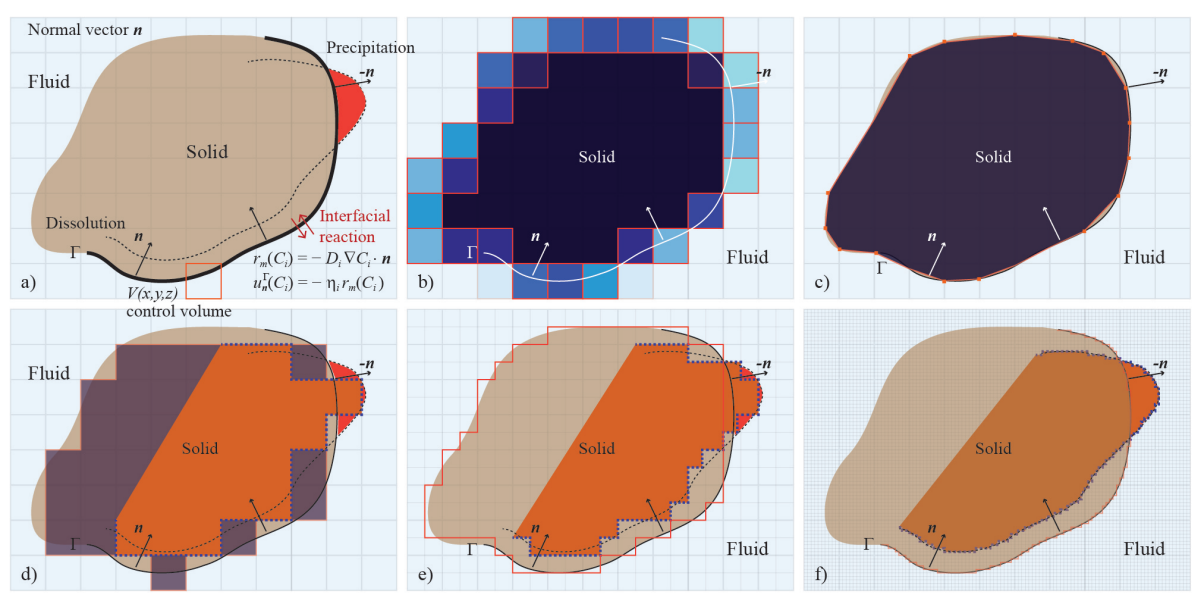

Fig. 1 Examples of interface $(\Gamma)$ representation and evolution thanks to interfacial reactions, i.e., dissolution or precipitation processes. (a) Interface representation in the physical domain (solid line) and evolution (dotted line) ; $\boldsymbol{n}$ is the vector normal to the surface. (b) Microcontinuum representation of the interface in control volumes (filtering-approach); each control volume has a porosity comprised in between the internal porosity of the solid (dark blue) and 1 (light blue, fluid phase). (c) Adaptive meshing of the interface. (d) Representation of the interface and its evolution (orange) using a Cartesian grid. The initial and final solid volumes (or their envelope, i.e., the interface) are highlighted with dark blue \& solid line or orange \& dotted line, respectively. (e-f) Effect of increasing resolution on the interface and object definition shown in (d). Note that (d-e) are similar to what can be derived from XMT at three different imaging resolutions.

mineral $j$ ). Several methods, from simple thresholding to more complex algorithms based on the voxel intensity distribution or the object shape can be used $[64,56,118]$. The performance of segmentation methods is limited by the image dynamics, i.e., the distribution of the voxel intensity. It depends on the degree of interplay or separation between the different modes (i.e., phases) in the distribution, the amount of noise and artifacts inherent to the acquisition and reconstruction techniques, and the possible existence of partial volume effects. Recently, techniques of segmentation based on machine learning methods, e.g., convolutional deep neural networks, are booming [8, 40]. These methods are particularly helpful to retrieve poorly-resolved interfaces in multi-crystalline or multi-porosity rocks, although it may require additional material at a higher resolution, e.g., scanning electron microscopy (SEM) images in supervise training approaches $[67,99]$. After segmentation, the interface between two phases is defined at the boundary between two voxels with a different label.

Surface topography evolution of sharp interfaces. Subsequent alignment of the segmented volumes is required to evaluate the interface topography evolution with time. Registration is an important step of the image processing procedure for comparing data sets with each others. Registration consists in a spatial transformation determined by optimizing a similarity metrics, e.g., invariant moments, cross-correlation or mutual information. When there is no mechanical deformation of the sample, it consists in a rigid transformation involving 3 rotations and 3 translations around the $x-, y$-, and $z$-directions, combined with interpolation. Whether the imaging experiments are performed in situ (i.e., directly in the X-ray beamline) or ex situ (i.e., 
removed from the beamline between two acquisitions), the resulting data sets at increasing acquisition time are slightly to largely rotated and translated relative to each other. Misalignment of data sets results in error of the interface retreat measurement between two stages of experiment. Misalignment can be corrected by registering the data sets in a reference coordinate system. Registration is preferred on the grayscale data sets, i.e., prior to segmentation, to avoid a rough re-interpolation of the interface position on already segmented data sets. Many methods exist to perform registration ranging from landmark-based registration to optimized algorithms based on image intensity, image features or neural network [85,162]. Registration starts generally with the first XMT volume used as the reference data set, and all the other data sets are registered to this volume. However, for self-running registration algorithms, if the sample geometry evolution is large during the experiment, it is better to register a given data set thanks to the one previously registered. This has the effect of minimizing the effects of the geometry evolution on the optimization algorithms.

(i) Flat interfaces. It is possible to evaluate locally the topography evolution of a specific interface of an object by registering the mean plane of the original surface in a horizontal plane, then projecting the surface elevation normal to the mean plan on a 2D Cartesian grid (Figure 2). The same transformation applied to the other topographies at increasing time gives the evolution of the interface position. This method, which is routinely used with two-dimensional techniques measuring the surface topographies, e.g., Atomic Force Microscopy (AFM) or Vertical Scanning Interferometry (VSI) $[142,15,47]$, is convenient as it permits to manipulate the data on a $2 \mathrm{D}$ discrete grid. It can be used to observe the topography evolution of fracture walls $[57,107,105]$ or fluid-crystal interface $[109,108]$ using 3D XMT. This method, however, is valid for flat surfaces only. For rough surfaces, the inclination of surface elements introduces an error in the retreat determination. The error in the determination of the surface retreat is estimated using,

$$
\left\|h^{\prime} \cdot \boldsymbol{n}^{\prime}\right\|=\cos \theta \times\|h \cdot \boldsymbol{n}\|,
$$

where $\boldsymbol{n}^{\prime}$ is the normal to the reference plane, $h^{\prime}$ is the surface elevation normal to the reference plane, $\boldsymbol{n}$ is the normal to the mean local surface plane, $h$ is the surface elevation normal to the mean local surface plane, and $\theta$ is the angle formed by $\boldsymbol{n}^{\prime}$ and $\boldsymbol{n}$ (Figure 2). If $\theta$ is superior to $25^{\circ}$, the error in the determination of the surface retreat is more than $10 \%$.

(ii) Curved or complex interfaces. For curved or steep surfaces, projections normal to the mean plane generate an error in the determination of the interface elevation. As for complex interfaces with overlaps, like rough surfaces resulting from differential dissolution of minerals [57], the projection of the surface normal to the mean plane requires the selection of only one interface, whereas several may exist at the same $(x, y)$ location. Consequently, it leads to a simplistic representation of the fluid-rock interface (see also Figure 2 where fine particles or insoluble minerals are present at the surface) and introduce bias in the surface retreat measurement, the evaluation of the fluid-rock interface position and the surface roughness calculation. In these cases, it is preferable to work with the full $3 \mathrm{D}$ digital representation of the solid phase after segmentation to track the interface evolution or to calculate the mass balance. In any case, it is possible to get an explicit representation of the interface directly from the 3D digital images, after mapping of the labelled solid and fluid voxels into a regular Cartesian grid. Adaptive mesh refinement methods based on level set, phase field, volume-of-fluid or conforming meshes also offer the possibility 

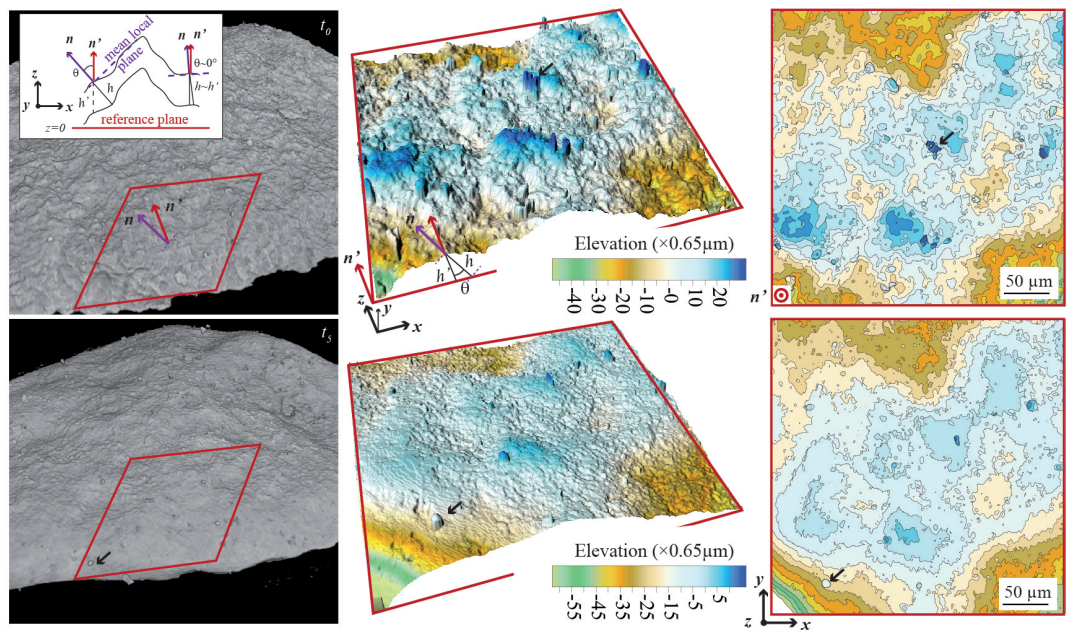

Fig. 2 Extraction and mapping of the fluid-rock interface topography evolution from a 3D rock volume (left) to a $2 \mathrm{D}$ Cartesian grid (right). The red square is $512 \times 512$ pixels in size, and the mean surface plane was set to $z=0$ for the topography at $t_{0}$. The sample is a limestone aggregate imaged with a pixel size of $0.65 \mu \mathrm{m}$ initially $\left(t_{0}\right)$ and after $12 \mathrm{~h}\left(t_{5}\right)$ of a dissolution experiment in a high fluid-to-rock ratio reactor using $\mathrm{HCl}$ at $\mathrm{pH}=4.0$. Meantime the retreat was $15.0 \mu \mathrm{m}$ in average. Note the presence of fine particles and quartz grains at the surface (black arrows) which affect locally the interface elevation. The frame (top left) shows the problem inherent to interface retreat determination for non-flat interfaces, when the mean local surface plan is tilted with respect to the reference surface.

to refine in the computational domain the interface obtained from XMT images [94, 97]. These methods are particularly adapted to further track the interface motion. Direct surface meshing of the complex interfaces is also possible from the $3 \mathrm{D}$ digital images, for instance using triangulation methods.

Dealing with smeared interfaces. In rocks with multi-modal distribution of porosity, like in poorly-sorted sandstone or bioclastic limestone, the pore space is commonly irregular and not sufficiently resolved to extract the fluid-mineral or fluid-rock interfaces, which remain poorly defined. The same problem applies to other rocks, e.g., silt or shales, when XMT imaging resolution is too low regarding the pore size. In these cases, the locations straddling several materials are affected with partial volume effects, which result from a limited spatial resolution of the imaging technique compared to pore size. A voxel affected with partial volume effects depicts a grayscale intensity (absorption value) balanced by the quantity of the different materials included in this portion of space (Eq. 2). Segmentation often leads to a misrepresentation of the fluid and solid phase distribution in that case. Multi-scale imaging $[63,52,91]$ possibly involving local tomography technique [86] is helpful to differentiate the smallest pores in small volumes of interest (VOI) and allows for a better estimate of the micro-porous network topology and micro-porosity. Nevertheless, it is worth noting that segmentation is not mandatory for all the pore-scale modelling approaches. For example, hybrid modelling and filtering approaches based on the Darcy-Brinkman approach $[132,127,14]$ permits to account for the microporosity which is not resolved with XMT (Figure 1b). In addition, it is also possible 
to calculate the porosity of a growing, smeared and porous interface directly from the grayscale images. The porosity is derived from the absorption properties of the individual materials forming the unaltered rock matrix, i.e., pores (air) and minerals $i$. If the mineral assemblage is homogeneous, minerals have similar absorption properties and the unaltered matrix porosity is null, the unaltered matrix has an attenuation coefficient $\left(\mu_{\text {mat }}\right)$ similar to the linear attenuation coefficients of the matrix-bearing minerals $\left(\mu_{\min _{i}}\right)$. The porosity of the altered matrix is then given by [100]:

$$
\phi=\left(\mu_{m a t}-\mu_{T}\right) /\left(\mu_{m a t}-\mu_{a i r}\right),
$$

where $\mu_{\text {mat }} \approx \mu_{\text {mini }}, \mu_{T}$ is the attenuation of the altered matrix, and $\mu_{\text {air }}$ is the linear attenuation coefficient of air. However, if the unaltered matrix is initially micro-porous, then $\mu_{m a t} \neq \mu_{m i n_{i}}$, and $\mu_{m a t}$ must be corrected in Eq. 4 to account for sub-voxel porosity:

$$
\mu_{m a t}=\left(1-\phi_{m a t}\right) \times \mu_{m i n_{i}}+\left(\phi_{m a t} \times \mu_{a i r}\right)
$$

Figure 3 shows an example of porosity field estimation based on XMT in an argillaceous limestone fracture altered by acid fluid, where carbonate minerals (calcite and dolomite) dissolve while low-reactivity silicates (clays and quartz) remain in the matrix [107]. Consequently, the fluid-rock interface evolves from a sharp (initially) to a smeared, diffuse interface because the altered layer in the porous matrix is not fully resolved by the imaging instrument resolution. The porosity increase calculated in the altered layer is highly consistent with the amount of dissolved carbonates in the matrix.

2.3 Evaluation of displacement and local reaction rates for evolving fluid-mineral interfaces

The interface displacement results from the transient, non-linear coupling between transport of species and chemical reactions in the vicinity of the fluid-rock interface. Determination of reaction rates at the mineral or rock scale requires first an evaluation of the interface displacement, i.e., the interface retreat (or motion) function through time. Because the interface position is defined on a Cartesian grid, two ways appear to measure the displacement, which is equivalent to measuring the distance between two surfaces. The first is achieved through the extraction and meshing of the interface topography at different time steps. This method requires less memory compared to working directly with the $3 \mathrm{D}$ data sets, and also offers the possibility to smooth the sharp, cubical-shaped interfaces obtained by segmentation. The second consists in computing the 3D distance field, also called distance map or distance function, on a reference volume, starting from the interface which constitutes a zero level set, and looking at the intercept of the distance map with the interface at another time step. Both methods are convenient to further measure the interface displacement rate or the reaction rate, as already shown in studies focusing on dissolution of fracture walls [100], mini-boreholes [66] or minerals $[100,109,108,160]$ or precipitation in porous media [112]. 

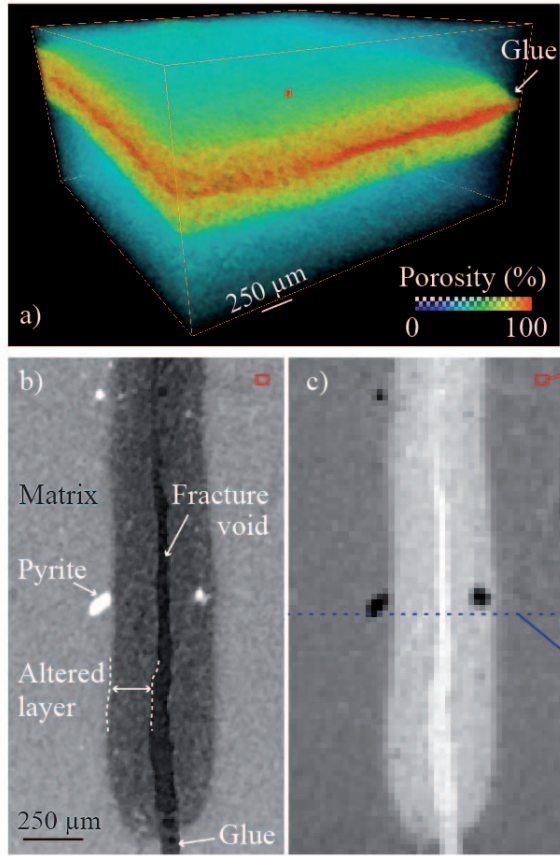

Low Attenuation High

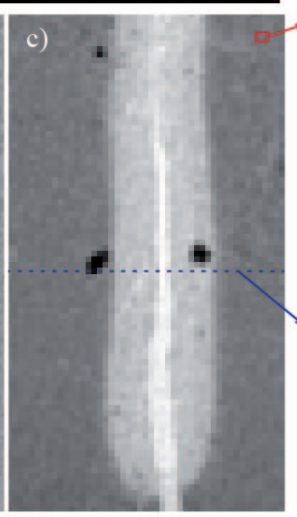

Porosity (\%)
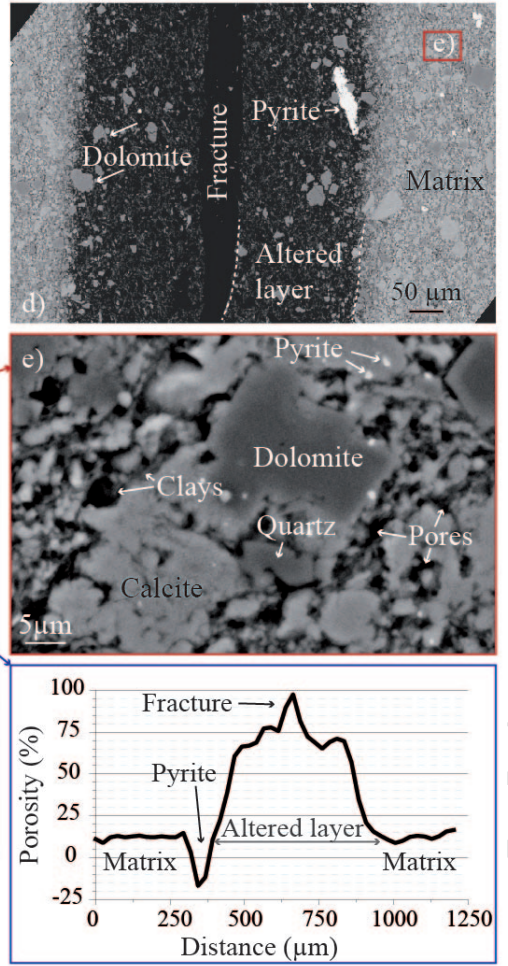

$255 \quad-75 \quad 0 \quad 10$

100

Distance $(\mu \mathrm{m})$

Fig. 3 (a,c) Porosity field map of an altered fracture derived from (b) XMT imaging, where an altered interfacial layer of silicates (clays + quartz) has developed for 99.5h of dissolution by $\mathrm{CO}_{2}$ enriched water $\left(\mathrm{pH}=3.9\right.$ and flow rate of $300 \mathrm{~cm}^{3} \mathrm{~h}^{-1}$ ) of the carbonate phase held in the argillaceous limestone matrix; (d) comparison with SEM observation. The rock is $\sim 73 \%$ carbonates (calcite + dolomite) and contains $\sim 27 \%$ of low-reactivity minerals (clays, quartz, and pyrite). The pore size given by SEM analysis is micrometric (e), but only pores $>100 \mu \mathrm{m}^{2}$ could be resolved with XMT imaging at the resolution (pixel size) of $4.91 \mu \mathrm{m}$. The attenuation coefficient of the unaltered matrix $\left(\mu_{\text {mat }}\right)$ is weighted by the porosity of the rock $(10 \%)$, and the porosity of fracture void is set to $100 \%$. The average porosity of the altered matrix derived from XMT (75\%) near the fracture void, i.e., where all the carbonates have been dissolved, is in very good agreement with the amount of minerals remaining in the altered matrix (26\% silicates). Note that the presence of pyrite, whose attenuation coefficient $\mu_{\text {pyrite }}$ is very different from the other minerals ( $\left.\mu_{\text {silicates }} \sim \mu_{\text {carbonates }}\right)$, alters locally the porosity evaluation (resulting in $\phi<0 \%$ ). The red rectangles give the scale of image (e). See [107] for more information about the experimental study.

Surface retreat from interface topography meshing. The first step before measuring the displacement rate of the interface consists in extracting and possibly meshing the interface at the different time steps. Extraction of the interface is possible from the registered binary or labeled data sets. Pixels at the interface between solid and fluid voxels can serve as square elements to directly create a mesh at the XMT imaging resolution. Triangular or tetrahedral elements are also commonly used to create a mesh. Mesh generators offer many possibilities in term of refinement, simplification or smoothing of the original surface [42]. Once two surfaces are extracted, the next step consists in computing the distance between them. This is achieved by computing the normal vectors from the reference surface $\mathrm{S}\left(t_{i}\right)$, then projecting normal rays 
until they intercept the second surface $\mathrm{S}\left(t_{j}\right)$. The choice of the reference surface is important (Figure 4), especially for convex or concave surfaces, as: $(i)$ propagation distance depends intimately on the curvature of the interface, convex regions propagating slower than concave regions [129], and ( $i i)$ changes in surface area during their expansion or constriction modify undoubtedly the number of elements from which the normal vectors are projected, and consequently the displacement distribution (Figures $4 \mathrm{a}$ and $5 \mathrm{c}, \mathrm{d}$ ).

In some cases, it is possible to extract directly the interface topography from the binary data sets, i.e., without meshing. This method is particularly fast and convenient but requires the topography of the interface to be quite flat or smooth, like fracture wall surfaces [100], or cleaved mineral surfaces [108]. The surfaces must be replaced as well in a horizontal or quite horizontal plane (see Figure 2 and section $2.2)$.

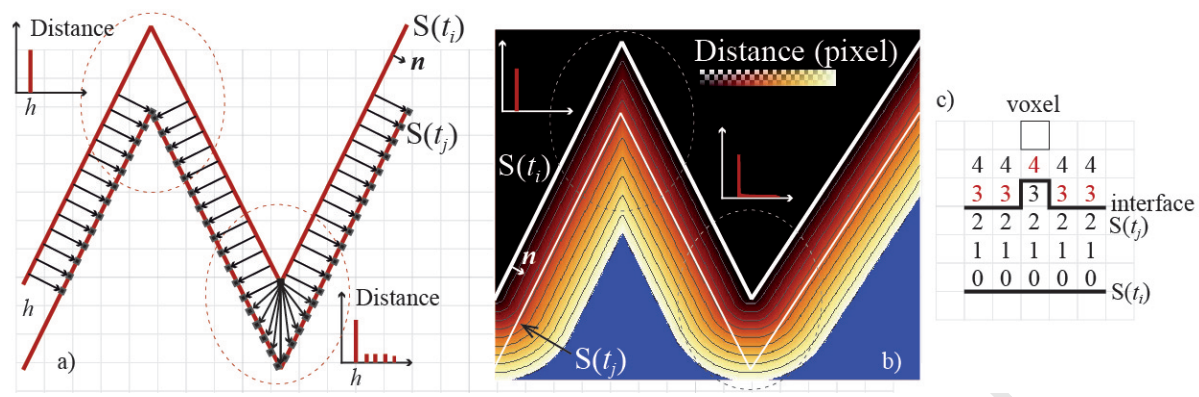

Fig. 4 Illustration of the problem of curved interfaces and choice for a reference surface for the interface displacement evaluation; (a) evaluation from the propagating distance vectors; (b) evaluation from the Euclidean distance field. In the present case, $\mathrm{S}\left(t_{i}\right)$ is used as the reference surface to propagate normal rays that will intercept the translated surface $\mathrm{S}\left(t_{j}\right)$. Note the difference in the distance distributions in areas of sharp convexity or concavity; (c) Chamfer distance field using the interface at $\mathrm{S}\left(t_{i}\right)$ as a reference. The values in red correspond to the displacement of the interface (in pixels) between $\mathrm{S}\left(t_{i}\right)$ and $\mathrm{S}\left(t_{j}\right)$.

Surface retreat from the distance map construction on $3 D$ images. The distance transform is another way to evaluate surface displacements in $3 \mathrm{D}$ data sets. It consists in propagating the interface along its normal vector field inward or outward (i.e, either in the solid or the fluid phase) with a constant rate, thus labeling progressively the different voxels with discrete values, e.g., using a chamfer distance-based algorithm, or with continuous values through the Euclidean distance calculation [3, 126] (Figure 4b,c). The method consists in mapping the distance field in the reference volume $\mathrm{V}\left(t_{i}\right)$, starting from the reference interface $\mathrm{S}\left(t_{i}\right)$, which constitutes the zero level set. The intercept of the distance field with the closest voxel to the second interface $\mathrm{S}\left(t_{j}\right)$ on volume $\mathrm{V}\left(t_{j}\right)$ gives the interface displacement during $d t=t_{j}-t_{i}$ (Figure $5 \mathrm{c}$ ). Taking the closest voxels to the interface is justified by the fact that the distance is measured between two boundary voxels while distance values are defined at the voxel centers (Figure 4c). The choice of the reference surface is important, especially for dilating or constricting surfaces, in direct relationship with the interface curvature (Figures 4b and 5e,f). For instance, Noiriel et al., 2019 [109] map the distance field inside a cleaved calcite crystal (i.e., inside the solid phase) 
during dissolution using the initial crystal as the reference volume, and look at the intercept with the fluid-mineral interface at increasing stages of dissolution (i.e., for $t_{j}>t_{i}$ ). That way, the surface retreat is calculated as the shortest distance to the closest cleaved (1014) plane, which is more logical from a mechanistic point of view. The opposite approach consists in taking $\mathrm{V}\left(t_{j}\right)$ as the reference volume, then mapping the distance field outward of $\mathrm{S}\left(t_{j}\right)$ (i.e., in the fluid phase) and looking at the intercepts with the interface $\mathrm{S}\left(t_{i}\right)$ at the previous stages of experiment (i.e., for $\left.t_{i}<t_{j}\right)$. This is equivalent to measuring the interface retreat normal to any element of the crystal surface instead of the retreat normal to the cleaved planes. The latter case, however, leads to an overestimation of the reaction rate at the crystal edges (Figure 5). Nevertheless, Noiriel et al., 2020 [108] used this last method, motivated by the fact that: $(i)$ the distance map is recalculated at any time step to accounts for the changes of crystal morphology at the edges and corners in different experimental conditions, and (ii) the crystal has a morphology far more complex than a simple rhombohedron with only cleaved faces and sharp convex edges and corners, especially after dissolution has proceeded. The last method permits to measure the dissolution rate at the crystal surface regardless a strong assumption on the crystal geometry. Even if the highest rates at the edges are overestimated at the beginning of the experiment, it is possible to catch correctly the evolution of their distribution with time.

To summarize, there is no unique solution in computing the distance between two surfaces, and the method must be adapted to the problem under study. In porous media, the choice of the reference is crucial as well, as the pore throats and pores have opposite curvature. Depending on whether the focus is put on pores or pore throats, the choice of the reference surface might balance between $\mathrm{S}\left(t_{i}\right)$ and $\mathrm{S}\left(t_{j}\right)$. If the focus is put on the pore-throat enlargement rate, in relationship with permeability for instance, it is preferable to use $\mathrm{S}\left(t_{j}\right)$ as the reference surface. In addition, it is worth noting that these methods could fail when applied to the evolution of complex interfaces (Figure 6), especially when isolated solid aggregates, e.g., fine particles, totally dissolve or are largely displaced between two time steps, a common effect occurring during dissolution in porous media [104,101,87].

Reaction rate. From the evaluation of the interface displacement, it is possible to calculate the local reaction rate at the surface according to:

$$
r^{\prime}{ }_{d i s s}=\frac{d \boldsymbol{I}_{\boldsymbol{f} \boldsymbol{s}} \cdot \boldsymbol{n}}{d t}
$$

with $\boldsymbol{I}_{\boldsymbol{f} \boldsymbol{s}}$ the position vector of the interface, and $\boldsymbol{n}$ the normal vector to the fluidmineral interface; the product $d \boldsymbol{I}_{\boldsymbol{f} \boldsymbol{s}} \cdot \boldsymbol{n}$ is the surface displacement, i.e., the distance normal to the interface. The rate for a mineral $i$ is expressed as a retreat velocity at the surface (nm s$~^{-1}$ or $\mu \mathrm{m} \mathrm{h}^{-1}$ ), but can also be averaged at the sample scale and normalized to the surface area [15]. For flat surfaces (see section 2.2), the equation simplifies:

$$
\bar{r}_{\text {diss-norm }}^{\prime}=\sum_{j_{\text {sol-fluid }}} \frac{1}{\eta_{i} \times j_{\text {sol-fluid }}} \frac{d \boldsymbol{I}_{\boldsymbol{f} \boldsymbol{s}} \cdot \boldsymbol{n}}{d t},
$$

with $j_{\text {sol-fluid }}$ the number of voxels at the fluid-mineral $i$ interface, and $\eta_{i}$ the molar volume of mineral $i$. 

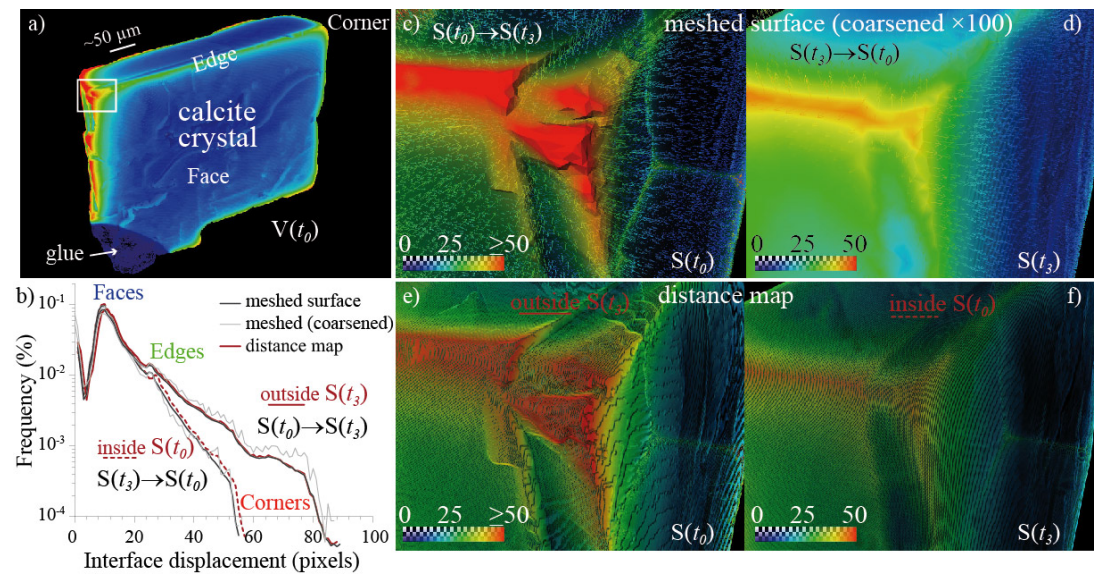

Fig. 5 (a,b) Surface retreat distribution imaged with XMT during crystal dissolution as a function of the method employed to calculate the retreat (i.e., surface meshing versus distance field), the degree of simplification of the interface (meshing refinement) and the reference surface used in the calculations. The sample is a crystal of calcite imaged with a resolution of $0.65 \mu \mathrm{m}$ (pixel size). Two time steps are shown here: $t_{0}$ (initial state) and $t_{3}$, i.e. after 6 hours of dissolution at by $\mathrm{HCl}$ at $p H 4.0$. Note that the main differences on the histogram are observed at the crystal edges and corners. (c,d) Evaluation of the surface retreat from mesh generation and coarsening by a factor 100 (the interfaces are meshed with $\sim 10^{6}$ triangular elements for $4-510^{6}$ pixels defining the interface in the original XMT data sets); in (c), the reference surface is $\mathrm{S}\left(t_{0}\right)$, and the normal rays are projected toward $\mathrm{S}\left(t_{3}\right)$; (d) represents the opposite case. (e,f) Surface retreat derived from Euclidean distance field generation; in (e) the distance map is computed outside of $\mathrm{S}\left(t_{3}\right)$ and combined with $\mathrm{S}\left(t_{0}\right)$, whereas is it computed inside of $\mathrm{S}\left(t_{0}\right)$ in (f). See [109] for more information about the experiment.
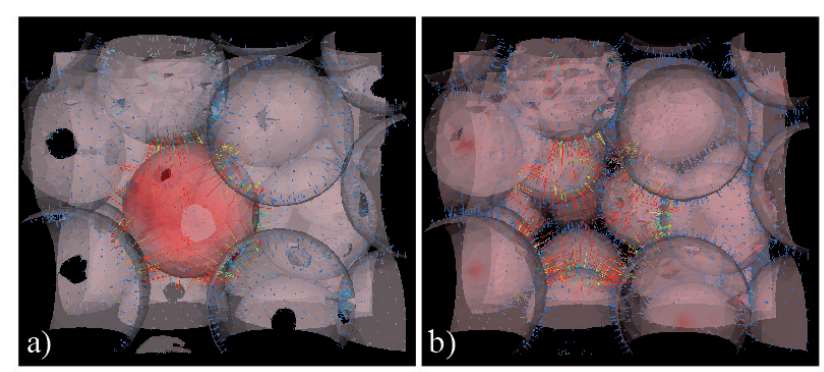

Fig. 6 Effect of disappearance of a solid object (e.g., a grain or a fine particle) between two stages of dissolution, that leads to an improper estimation of the displacement vectors. The image is derived from 3D imaging of glass bead packing. Image processing is used to illustrate a uniform erosion of the grains, apart from one bead removed to mimic full dissolution. a) Volume rendering of the initial image with the displacement vectors; b) Volume rendering of the final image with the central bead removed. The same displacement vectors are shown. The length of the arrows is proportional to the displacement.

\section{Direct modelling of reactive flow}

Modelling dissolution processes at the pore scale requires efficient numerical algorithms to track the fluid-rock interface according to surface reactions. In this section, we recall the fundamental equations used for modelling hydro-geochemical processes 
at the pore scale, and we review the state-of-the-art computational approaches for solving them. Finally, we discuss hybrid-scale models for moving the interface between a porous domain and a clear-fluid region.

\subsection{Fundamental equations}

At the pore scale, the distribution of fluid and solid in the domain is fully resolved, and the two phases are separated by a sharp interface. The physics of flow and transport obeys the laws of continuum mechanics using mass, momentum, and species balance equations.

For single-phase incompressible and Newtonian fluid, the mass balance equation reads,

$$
\nabla \cdot v=0
$$

where $\boldsymbol{v}$ is the fluid velocity.

The momentum balance is described by the Navier-Stokes equation. It writes,

$$
\frac{\partial \rho \boldsymbol{v}}{\partial t}+\nabla \cdot(\rho \boldsymbol{v} \boldsymbol{v})=-\nabla p+\rho \boldsymbol{g}+\nabla \cdot \mu\left(\nabla \boldsymbol{v}+\nabla^{t} \boldsymbol{v}\right)
$$

where $p$ is the pressure field, $\boldsymbol{g}$ is the gravity, and $\rho$ and $\mu$ are the fluid density and viscosity, respectively. The left-hand side corresponds to the inertial effects. As mass flow rates in aquifers or reservoirs are usually low, it is common to neglect this term and to use Stokes instead of the Navier-Stokes momentum equation [73,31]. On the right-hand side, the first term is the pressure gradient, the second is the gravity acceleration and the third term is the viscous dissipation. At the pore scale, the density is assumed constant due to the relatively small changes in fluid composition, so that it is common to neglect the gravity term. Hence, the following momentum,

$$
0=-\nabla p+\nabla \cdot \mu\left(\nabla \boldsymbol{v}+\nabla^{t} \boldsymbol{v}\right)
$$

is often used instead of Eq. 9.

In its simplest form, the transport of a species $i$ in a fluid phase is modelled by an advection-diffusion equation:

$$
\frac{\partial C_{i}}{\partial t}+\nabla \cdot\left(\boldsymbol{v} C_{i}\right)=\nabla \cdot\left(D_{i} \nabla C_{i}\right)
$$

where the first term is the accumulation term, the second term is the advection term and the right-hand side corresponds to diffusion effects where $D_{i}$ is the diffusion coefficient of species $i$ into the fluid phase. More complex forms of the solute transport include multi-component diffusion, thermal diffusion and electrostatic gradients.

The flow and species transport equations are supplemented by boundary conditions at the solid surface. Total mass balance near the interface imposes that the mass flux from the fluid side balances the mass flux from solid side (see Fig.1a). Basically, all the dissolved mineral goes into the fluid. The continuity condition at the solid boundary writes,

$$
\boldsymbol{n} . \rho(\boldsymbol{v}-\boldsymbol{w})=\boldsymbol{n} \cdot \rho_{s}(-\boldsymbol{w}),
$$

where $\boldsymbol{n}$ is the normal vector to the fluid-rock interface, $\boldsymbol{w}$ is interface velocity, and $\rho_{s}$ is the solid density. For viscous flow, it is common to consider that the fluid 
molecules adhere to the surface due to molecular interactions including van der Waals or Coulombic forces. Because of this adherence, the fluid particles at the solid wall cannot slide on the surface and the tangential component of the velocity is null, leading to the no-slip condition at the moving interface,

$$
\boldsymbol{v}=\boldsymbol{w}\left(1-\frac{\rho_{s}}{\rho}\right) .
$$

A common assumption consists in considering a zero-velocity condition at the solid surface similar to non-reactive flow. This hypothesis is not always valid. As the solid density is usually larger than the fluid density, $\left(1-\frac{\rho_{s}}{\rho}\right)<0$, the fluid velocity at the wall and the interface velocity have opposite signs. Therefore, when the interface recedes because of mineral dissolution, there is a mass flux coming from the solid boundary to the bulk of the pore. The importance of this mass flux depends on the dissolution rates but also on the fluid-solid density ratio. The higher the density ratio, the stronger the mass flux.

The reactive flux condition when the chemical species reacts with the solid surface is,

$$
\text { n. }\left((\boldsymbol{v}-\boldsymbol{w}) C_{i}-D_{i} \nabla C_{i}\right)=r_{m}\left(C_{i}\right),
$$

where $r_{m}$ is the reaction rate, i.e., a source or sink term that describes reaction kinetics. Simple rate laws exist for zero, first, and second-order reactions. Except for the zero-order reactions for which reaction rates are independent of concentration, reaction rates depend on the species distribution near the fluid-rock interface. This dependency is responsible for the complex coupling between flow and surface reaction that transforms, for example, a cylindrical mineral into an elongated shape $[135,41$, $72]$.

The fluid-rock interface recedes during dissolution processes. The receding velocity, $\boldsymbol{w}$, of the moving boundary is obtained using mass balance near the interface. It reads,

$$
\boldsymbol{w}=V_{m} r_{m}\left(C_{i}\right) \boldsymbol{n},
$$

where $V_{m}=M_{m} \rho_{m}^{-1}$ is the molar volume, with $M_{m}$ being the molar mass of the solid mineral.

\subsection{Numerical engines}

Computational methods for solving the mathematical model formed by Eqs. (8)(15) are challenged by the moving boundary due to the dissolution or precipitation of solid minerals [133]. Many approaches have been proposed to track the fluidrock interface along with surface reactions. A comprehensive review of the numerical techniques for simulating pore-scale dissolution is found in [93]. Some intend to solve directly Eqs. (8)-(15) while others use a different set of equations that converges asymptotically to the solution of Eqs. (8)-(15). The benchmark problem presented in [93] led to the strong conclusion that all the techniques for moving fluid-rock interfaces are now mature enough to simulate with confidence pore-scale dissolution processes. In this section, we give a brief overview of the most common techniques for reactive transport modelling at the pore scale, including Computational Fluid Dynamics (CFD) with moving boundary, Level-Set, phase-field or micro-continuum, Smooth Particle Hydrodynamics (SPH), and Lattice Boltzmann Methods (LBM). 
CFD with moving mesh The pore space is decomposed into polyhedral cells and the partial differential equations Eqs. (8)-(11) are discretized using Finite Volume Methods (FVM), Finite Element Methods (FEM) or Finite Difference Methods (FDM). The no-slip (Eq. 13) and the reactive flux (Eq. 14) conditions are applied at the solid boundaries. The points at the pore walls are displaced using Eq. (15) and the grid is deformed accordingly. This technique is also referred to as Arbitrary LagrangianEulerian because the flow and transport equations are solved in an Eulerian frame and the grid points are moved using a Lagrangian approach. Complex re-meshing strategies can be required, in particular if a grain dissolves totally, which changes the domain topology. Examples for dissolution processes using CFD with moving mesh are found in $[114,140,139]$.

CFD with Level-Set The distribution of fluid and solid in an Eulerian grid is mapped using a Level-Set function. Within the Level-Set framework, the rock-fluid interface is represented by an isocontour. Larger isocontours represent the fluid phase and smaller values correspond the solid phase. The flow and transport equations are reformulated to include the mass flux conditions at the solid surface using immersed boundary methods. The Level-Set function is then advected using the interface velocity, Eq. (15), which describes the motion of the fluid-rock interface due to chemical reactions. This approach can handle complex pore space geometries using Cartesian grids only. Examples of pore-scale simulations of dissolution processes using Level-Set are found in $[95,97,96,77,76,62]$.

CFD with phase-field Unlike sharp-interface models such as Level-Set, phase-field approaches assume that the interface has a finite width and that a phase-field function describes smooth transitions in the different physical quantities between two phases. The diffuse interface usually smears over a few cells from both sides of the interface, and phase-field approaches are often combined with adaptive mesh refinement techniques to reproduce accurately the interfacial dynamics. Phase-field models are rooted in the concept of free energy. The evolution equation of the phase-field function is described either by the Cahn-Hilliard non-linear diffusion equation [30] or by the Allen-Cahn kinetic equation [6]. Examples of solid dissolution using phasefield approaches in grid-based simulations are found in $[156,157,155,158]$.

CFD with Volume-of-Solid and micro-continuum The solid phase is mapped onto an Eulerian grid using the volume fraction of solid minerals in every grid blocks. The technique is referred to as Volume-of-Solid by analogy with the Volume-of-Fluid approach used in CFD for tracking the fluid-fluid interface [61,24]. Mathematically, it relies on the asymptotic behaviour of the so-called micro-continuum approaches for modelling pore-scale processes [135]. In this approach, an algebraic set of partial differential equations that arises from the local averaging of Eqs. (8)-(15) is used all over the computational grid regardless of the content of grid blocks. The flow throughout the computational domain is modelled using the Darcy-Brinkman-Stokes momentum equation [27]. The solid phase is described by a fictitious low-porosity low-permeability material, which results in near-zero velocities in the solid regions and a no-slip boundary condition at the rock-fluid interfaces $[11,71]$. The reaction rate at the mineral surface, Eq. (14), is embedded in the locally-averaged species conservation law as a body source term that has non-zero values only in the cells that contain the fluid-rock interface. A conservation law that corresponds to the volume 
averaging of Eq. (15) for the solid mineral is used to move the fluid-rock interfaces during the dissolution. We will see in Section 3.3 that the micro-continuum approach can also be used to model the evolution of a fluid-porous interface. Examples of porescale simulations using the micro-continuum approach are found in $[135,136,134]$.

Smooth Particle Hydrodynamics SPH is a meshless method that describes fluids as a set of discrete moving particles tracked in a Lagrangian frame. The solid phase is also represented by immobile particles that enter into the calculation of forces acting on the fluid particles. All the particles have a sphere of influence over which their properties are smoothed by a kernel function centered on the particles [148]. The evolution of the fluid-rock interface is modelled by tracking the changes in the masses of the solid particles resulting from dissolution reactions. If the mass reaches zero, the solid particle is transformed into a new fluid particle. An example of SPH for reactive transport is found in $[145,146]$.

Lattice Boltzmann Methods Unlike CFD approaches that solve Navier-Stokes equations -or locally-averaged Navier-Stokes equations- LBM use another set of equations based on the gas kinetic theory whose averaged behaviour is known to approximate the law of continuum mechanics. In LBM, a discrete Boltzmann equation is solved on a lattice where the particles can only move along a finite number of directions. Examples of LBM for modelling dissolution at the pore scale are found in $[70,69,32$, $68,143,144,150,120,78,58]$.

\subsection{Multi-scale models}

Multi-modal pore-size distributions are quite common in geological porous media. In porous fractured media, for example, the width fracture is orders of magnitude larger than the typical pore throat diameter in the surrounding porous matrix. Approaches that consider only the fracture aperture evolution during dissolution as if the surrounding porous matrix was impermeable $[140,139]$ can miss important phenomena such as the development of a weathered zone near the fracture-porous interface. A full Navier-Stokes modelling, however, requires to resolve all the porosity explicitly, which leads to tremendous computational grid size. Alternative hybrid-scale models describe systems involving multiple characteristic length scales for which some regions are described using Navier-Stokes-based modelling while others are modelled with Darcy-like approaches $[80,79]$. In reactive environments, the challenge consists in moving fluid-porous interfaces including the transfer of mass and the development of an altered layer between the fracture and the porous matrix according to hydro-geochemical processes.

Hybrid-scale models are also relevant for image-based simulations for which microscale features are not visible in the images because they are below the imaging instrument resolution $[14,12,127,132,131]$. For example, they can complement and interpret micro-tomography images of the dissolution or sealing of a fracture $[107$, 2]. They are also powerful tools to analyze the micro-Raman mapping of mineral replacement in fractured porous media due to hydro-geochemical processes [119].

Standard approaches include the multi-domain approach that uses Darcy-Stokes and the micro-continum approach that relies on Darcy-Brinkman-Stokes. Other 
multi-scale approaches solve pore-scale equations (Eqs. 8-15) and Darcy-based models simultaneously.

Multi-domains using Darcy-Stokes The computational domain is decomposed into separate subdomains - one for regions that contain unresolved porosity (e.g. porous matrix) another for regions containing fully resolved porosity (e.g. fracture) - for which different physics are used. On the one hand, the flow and transport in the subdomains that contain unresolved porosity are described through continuum-scale models based on Darcy's law. The pore microstructure in these regions is modelled by classic concepts including porosity, permeability, and reactive surface area. The evolution of the pore geometries is described through permeability-porosity and surface area-porosity relationships. On the other hand, Stokes equations and standard advection-diffusion equations describe the flow and the solute transport in the resolved regions. Both subdomains are linked together through appropriate boundary conditions including the Beavers and Joseph interface condition [19] and the OchoaTapia and Whitaker's momentum transfer condition [113]. If the porosity in the porous subdomains becomes equal to one, then the fracture-porous interface is displaced using one of the strategies listed in Section 3.2. An example of multi-domain simulations using Darcy-Stokes is found in [94].

Micro-continuum with Darcy-Brinkman-Stokes These models use a single set of partial differential equations throughout the computational domain regardless of the content of a grid block $[141,137]$. The porosity field maps the porous medium distribution in the grid. The flow is modelled by the Darcy-Brinkman-Stokes equation [27] that tends towards Stokes momentum in solid-free regions and Darcy's law in porous regions [16]. In the latter region, classic continuum concepts including permeability and reactive surface area describe the sub-grid pore geometry. At the fracture-porous interface, the Darcy-Brinkman-Stokes equation formally tends to the Beavers and Joseph condition [98], and the micro-continuum approach captures the development of an altered layer during the dissolution of the porous matrix [137]. This approach enables the dynamic displacement of the interface between the porous and solidfree regions without involving complex re-meshing or interface tracking strategies. For example, micro-continuum models have been used successfully to simulate the formation and growth of wormholes in acidic environments [115, 55, 137, 45].

Multi-scale approaches These approaches solve the physics of flow and reactive transport at two scales of description simultaneously, namely the pore scale and the continuum scale [17]. They intend to provide large-scale solutions by minimizing the use of constitutive relationships that describe the evolution of the pore microstructure or transport properties (e.g. permeability-porosity law, mean reaction rate, and dispersion tensor). The continuum-scale equations are formally obtained by homogenizing pore-scale physics, and bi-directional algorithms couple the two scales [149, 159]. As the multi-scale approaches can become very computationally intensive, some strategies simplify the pore-scale mathematical problem using, for example, a unique circular grain that dissolve uniformly [26]. More sophisticated multi-scale approaches solve the complex hydro-geochemical feedback at the pore-scale using the techniques described in Section 3.2 for moving the fluid-rock interface during the dissolution [123]. Adaptive multi-scale strategies minimize the update of pore-scale physics only in cases of large evolution of the minerals geometry [59]. Although promising for 
solving reactive transport in large-scale domains, the multi-scale approaches are still in their infancy.

\section{Applications}

In this section we use image-based simulations to investigate various situations for which the fluid-mineral interface evolves according to surface reactions. First, we investigate the evolution of the surface roughness in an acidic environment under diffusion-limited transport. Then, we look at the fracture aperture increase during the injection of low $\mathrm{pH}$ brine considering either impermeable or porous matrix.

All simulations use porousMedia 4 Foam, an OpenFOAM ${ }^{\circledR}$ package that solves multi-scale flow and transport in porous media, including hydrogeochemical processes [134]. For all the simulations presented in this application section, we use a first-order kinetics to describe dissolution at the mineral-fluid interface. The rate of reaction (in $\mathrm{mol} \mathrm{m}^{-3} \mathrm{~s}^{-1}$ ) writes:

$$
r=A_{e} k_{H^{+}} C_{H^{+}},
$$

where $A_{e}$ is the surface area within a cell in $\mathrm{m}^{2} \mathrm{~m}^{-3}, k_{H^{+}}$is the constant of reaction in $\mathrm{ms}^{-1}$, and $C_{H^{+}}$is the concentration in $\mathrm{H}^{+}$in $\mathrm{mol} \mathrm{m}^{-3}$. This reaction rate may not be fully representative of the underlying geochemical processes. It is chosen to demonstrate the ability to move the fluid-mineral interface according to geochemical processes. More comprehensive reaction networks can be considered coupling multiscale transport codes with geochemical packages.

4.1 Fluid-mineral interface evolution in diffusion-limited transport conditions

The evolution of surface roughness in acidic environments has important impacts on many transport processes. Notable consequences include changes in absolute permeability [117], alteration of wettability [152], and reduction of the large-scale reaction rates caused by the presence of eddies within the roughness cavities [38]. Here, we investigate the evolution of surface roughness in diffusion-dominated regimes using high-resolution pore-scale simulations.

We consider a two-dimensional $512 \times 249 \mu \mathrm{m}^{2}$ domain that corresponds to the vicinity of the fluid-rock interface. The interface profile is derived from statistical properties (roughness and standard deviation of the surface elevation) calculated from the initial $512 \times 512$ surface topography presented in Figure 2. The solid phase is mapped onto the computational grid using the mineral volume fraction, $Y_{s}$ (see Figure 7). Volume fractions $Y_{s}=1$ denotes cells that contain the solid phase while $Y_{s}=0$ corresponds to cells occupied by water. Cells with intermediate values, $0<Y_{s}<1$, contain the fluid-rock interface. The initial roughness is $704 \mu \mathrm{m}$ long. In this illustration, there is no flow. The chemical species are transported by diffusion $\left(D_{i}=10^{-9} \mathrm{~m}^{2} / \mathrm{s}\right)$ from the bulk to the mineral surface where geochemical reactions lead to a retreat of the fluid-rock interface. Initially, the concentration of acid in the domain is zero. A fixed concentration value, $C_{H^{+}}=10^{-2} \mathrm{~mol} / \mathrm{m}^{3}$, is applied at the top boundary to describe a constant supply of $\mathrm{HCl}$ far from fluid-rock interface. The lateral boundary conditions are periodic, and the bottom boundary is impermeable. The reactive condition, Eq. (16), is applied at the fluid-rock interface using immersed boundary conditions. This is achieved using the Volume of Solid approach for which 
the surface of the fluid-rock interface within a grid block, $A_{e}$, is estimated from the gradient of the mineral distribution [135]. The evolution of the surface roughness is simulated during 500 hours for Damköhler numbers $D a=\frac{k_{H+}}{A e D_{i}}$ ranging from $10^{-1}$ to $10^{3}$ by varying the constant of reaction.

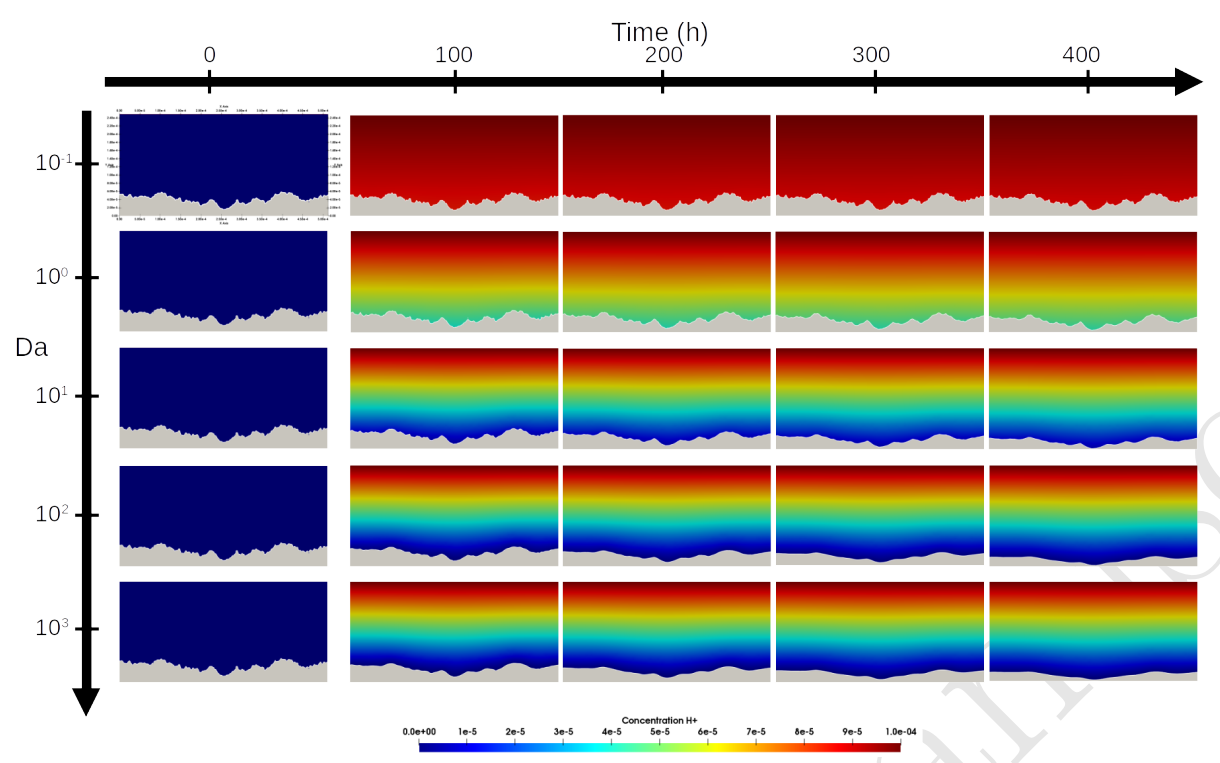

Fig. 7 Evolution of the surface roughness for different Damköhler ( $D a$ ) numbers in a diffusiondominated transport regime. For $D a<1$, the distribution of the chemical species at the fluid-mineral interface is uniform and the solid dissolves conserving the surface roughness. For $D a>1$, the peaks are dissolved before the topographical lows causing a flattening of the surface.

Results are presented in Figure 7. For low Damköhler numbers, i.e., $D a<1$, the characteristic time scale of species transport in the vicinity of the fluid-rock interface is much lower than the typical time of reaction processes at the mineral surface. Therefore, the species concentration is uniform at the solid surface and the interface recedes uniformly at the same velocity. During the mineral dissolution, we observe a translation of the interface towards the bottom of the domain with quasi conservation of the surface roughness. For larger Damköhler numbers, i.e. $D a>1$, the surface reaction is faster than the travel time of the chemical species to the fluidmineral interface. As the chemical species have a lower distance to travel to reach the peaks compared with the hollow regions of the roughness, there is a non-uniform distribution of reactants at the interface. These local concentration gradients favor the dissolution of the peaks which smooth down the roughness. The phenomenon is more pronounced for $D a>10$ as illustrated in Figure 7. The flattening of the surface roughness induced by mineral dissolution could explain, at least partially, the change of contact angle measured experimentally when a droplet of supercritical $\mathrm{CO}_{2}$ surrounded by brine is deposited on the surface of a reactive mineral [152]. The new possibilities offered by pore-scale simulators with evolving fluid-rock interface 
will be used to investigate the impact of surface roughness alteration on coupled hydro-geochemical processes.

4.2 Fluid-rock interfacial area evolution in dissolving rocks

Image-based simulations offer an appealing framework to investigate fracture-matrix interactions in reactive environments. The large contrast of characteristic length scales involved in fractured porous media - the typical pore sizes of the rock matrix and of the fracture aperture differ by several orders of magnitude - limits the use of very high-resolution images that fully resolve both the fracture and the matrix microstructure. Nevertheless, the presence of the surrounding porous matrix can impact the evolution of the fracture aperture by the development of a weathered zone at the vicinity of the fracture-matrix interface and must be included in the modelling. Here, we use pore-scale simulations to compare the evolution of a fracture geometry during the injection of acidic brine in two cases: (i) the rock matrix is impermeable and (ii) the rock matrix is porous.

The fracture geometry corresponds to the 3D micro-tomography images obtained in [107] and showed in Fig. 3 . The $25 \times 100 \times 165$ VOI was segmented into fracture void and matrix using a region growing algorithm [118]. For the simulations, we consider that the reacting matrix contains only calcite. The mineral distribution is mapped onto a $25 \times 100 \times 165$ Cartesian grid directly derived from the segmented VOI. Two $75 \mu \mathrm{m}$ long manifolds are added at the inlet and outlet of the computational domain to facilitate injection conditions. An aqueous solution at $\mathrm{pH}=2$ is injected for 100 hours. A pressure difference between the inlet and the outlet, $\Delta P=0.6 \mathrm{~Pa}$, is applied throughout the injection of solute in the system. The resulting flow rates are in the order of $100 \mathrm{~cm}^{3} / \mathrm{h}$ as reported in [107].

In both cases, the micro-continuum approach is used for solving Stokes equations in the fracture and Darcy's law in the matrix. A Kozeny-Carman law allows switching automatically from Stokes (in the fracture) to Darcy (in the matrix) whenever the local porosity, $\phi$, is smaller than 1 . The fracture-matrix interface is displaced according to chemical reactions that modify the porosity, which subsequently updates the local permeability field and then the flow profile. The impermeable and porous matrix cases differ, on the one hand, by the initial permeability and porosity values, and on the other hand, by the model used to compute the mineral-fluid surface area, $A_{e}$, in each grid block. In the first case, a fictitious low-porosity low-permeability matrix is used to describe impermeable boundaries (initially, $\phi_{0}=0.001$ and $k_{0}=10^{-20} \mathrm{~m}^{2}$ ). Porosity value between 0 and $1(0<\phi<1)$ denotes computational cells that contain the sharp fluid-rock interface. The volume of solid approach [135] uses the gradient of the mineral volume fraction, $Y_{s}$, to compute the surface area from the fracture geometry and apply surface reaction at the rock-fluid interface. In the porous matrix case, the matrix porosity and permeability are initially $\phi_{0}=0.2$ and $k_{0}=10^{-13} \mathrm{~m}^{2}$, respectively. The displacement of a porous-fluid interface is a two-scale problem and accurate modelling depends on the constitutive law used to describe the mineral surface area within a computational grid block. For the fracture-matrix interface, it seems relevant to assume that the species transport from the fracture to the host matrix is dominated by diffusion. Therefore, in the simulations, the surface area within a computational grid block evolves according to a power-law, $\frac{A_{e}}{A_{0}}=\left(\frac{Y_{s}}{Y_{s, 0}}\right)^{n}$, 

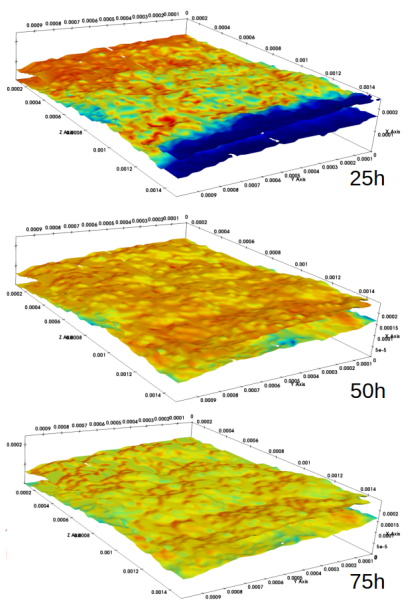

A

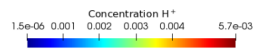

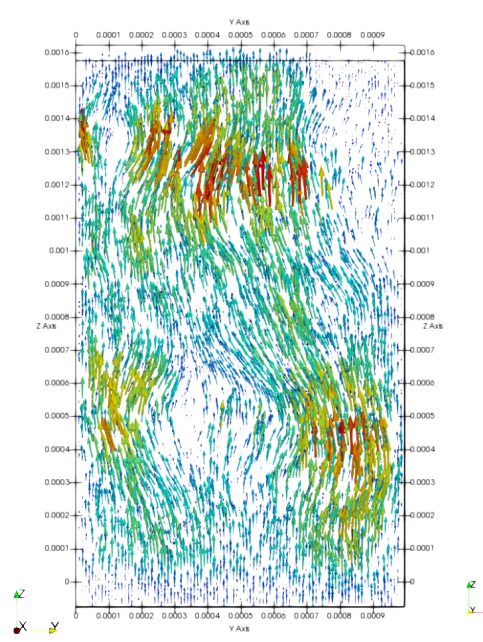

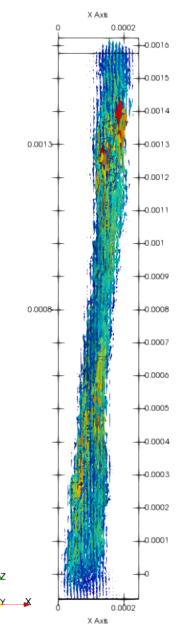

$\mathrm{B}$

Fig. 8 Fracture response to the injection of $\mathrm{HCl}$. (a) Evolution of the fracture aperture after 25, 50 and 75 hours. (b) Velocity vectors within the fracture. The non-uniform aperture of the fracture results in a heterogeneous velocity pattern with faster and slower flow regions.

where the initial surface area of the host matrix is $A_{0}=6500 \mathrm{~m}^{2} / \mathrm{m}^{3}$ and $n=2 / 3$ is a geometric parameter [106].

The fracture aperture evolution results from a complex interplay between advection, diffusion, and surface reaction. As illustrated in Fig. 8b, the velocity profile within the fracture is heterogeneous with fast flow regions and slower flow regions due to the topology of the fracture boundaries. In advection-dominated transport regimes, the faster flow pathways preferentially drive the reactant which leads to a non-uniform dissolution of the fracture surface, a phenomenon known as channeling [139]. Using impermeable boundaries, the mass of solid mineral decreases by $10 \%$ between the initial and final stage of the acid injection (see Figure 8a and Figure 9a). As the fracture aperture increases, the system permeability - estimated to be initially $10^{-10} \mathrm{~m}^{2}$ - increases by $150 \%$ after 100 hours of $\mathrm{HCl}$ injection. The presence of a porous host matrix strongly impacts the evolution of the fracture aperture and of the sample permeability. We obtain a decrease of the mass of calcite by $6 \%$ as well as a permeability increase of $50 \%$. Unlike the evolution of the fracture aperture within an impermeable host matrix that is always sharp, the porous-fluid interface can be diffused forming a weathered zone as observed in Figure 9b. The development of this altered layer depends on the penetration length of chemical species into the host matrix that varies according to the interplay between advection, diffusion, and surface reaction $[37,39]$. The simulations presented in this part highlight the capabilities of the micro-continuum approach to capture the development of altered zones. Nevertheless, accurate modelling of the fracture-matrix interface using hybrid-scale models needs a proper description of the matrix properties evolution during geochemical processes. According to matrix mineralogy, other constitutive laws can be more relevant. For example, in the case of the dissolution of an aggregate of mineral particles, the sugar-lump model [106] increases the surface area per unit of volume 

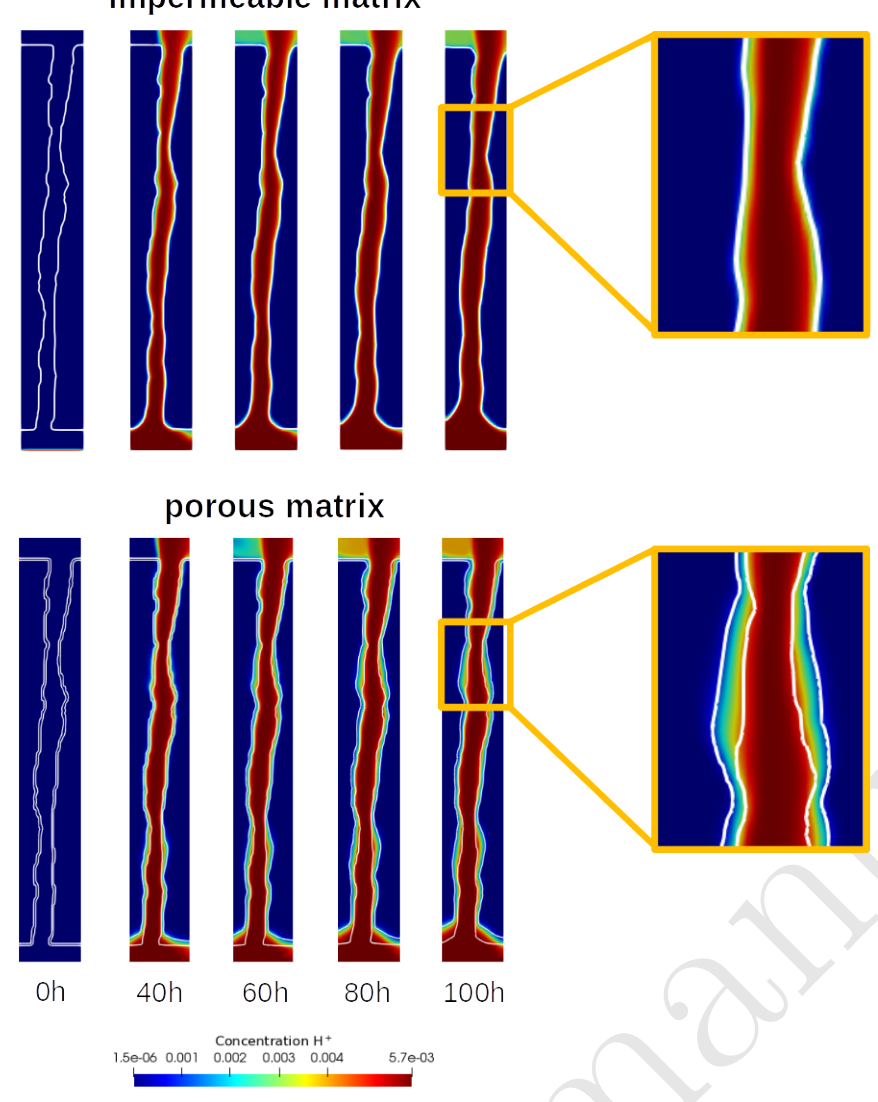

Fig. 9 Two-dimensional cross-section of the fracture aperture, with the host matrix either impermeable or porous. The white lines correspond to porosity isocontours $(\phi=0.5$ for the impermeable case, and $\phi=0.4$ and $\phi=0.25$ for the porous case). Notes the development of an altered layer due to the lateral penetration and reaction of the acidic solution into the host matrix.

while the power-law used in the present simulations decreases the specific surface area. Further investigations will focus on the characterisation of the altered layer thickness according to the Péclet and the Damköhler numbers.

\section{Discussion, conclusion and future challenges}

This article has presented two applications of interface displacement by dissolution in different mineral reactivity contexts. We have shown that the evolution of the interface is highly dependent on the coupling between chemical reactions and transport in the vicinity of the interface. For dissolution of a homogeneous rock in a pure diffusive context, the interface geometry evolution is highly dependent on the Damköhler number. At low $D a$, coupled processes result in a translatory displacement of the interface, whereas the surface roughness is largely affected at high $D a$. The Péclet number $P e \propto \frac{v l}{D_{i}}$, although not investigated in the present study, provides also useful 
information about the evolution of a particular system, by weighting the relative contribution of advective to diffusive transfer. Combined with the Damköhler number, it plays a role at a larger scale in determining the different dissolution regimes [55]. For dissolution in advective-diffusive contexts, the evolution of the interface is also highly dependent on the matrix properties. Whereas dissolution of a homogeneous and impermeable matrix leads to a sharp displacement of the interface, dissolution of a porous matrix results in the formation of an altered layer between the fluid phase and the unaltered matrix.

\subsection{Precipitation process}

The applications presented in this article concern dissolution processes. Precipitation associated with the evolution of fluid-mineral interfaces and reorganization of the flow paths plays also an important role in porous media $[76,145,146,111,54,102]$. Modelling precipitation processes is more challenging than dissolution as it requires more complex descriptions at all scales. In particular, although closely related to supersaturation and kinetics, the problems of nucleation and crystal growth at the pore scale generate severe unknowns on the reactive transport modelling methodology. For instance, accounting for nucleation, which is largely dependent on the free surface energy of the substrate $[46,112]$ and to induction time requires a probabilistic approach to initiate nucleation at the interface. In addition, growth largely depends on the crystal lattice, with very different crystal habits between minerals, and their shape can also be largely modified thanks to the presence of minor elements or organics in solution [25]. Additional variation in growth rate of different crystal facets, as the role of micro-organisms, development of crystallographic preferred orientations, changes in specific surface area, competition for growth between neighbouring crystals, ability of the smallest pores to maintain a higher saturation with respect to crystallisation or Ostwald ripening $[36,121,60]$ makes the evaluation of the crystallisation process evolution through time and space difficult. The level set method [76,129] appears presently one of the most promising method to handle the growth dynamics, although there is no clear way yet to account for all the constrains above-mentioned. Additional experimental effort involving digital core analysis or microfluidic device $[53,111,119,122]$ is still required to investigate real rock samples or representative analogues in presence of oversaturated fluids. Indeed, it is possible that mineral substrate and crystal growth heterogeneities (Figure 10) have a larger impact the flow field or pore-space heterogeneity on the reorganization of flow and sealing capacity of the pore space $[110,102]$. A special focus on mineral nucleation and growth is relevant to improve the understanding of the interface dynamics and the coupling of simulations with different scale-dependent physics.

\subsection{The challenge of upscaling}

Thanks to advances in non-destructive imaging techniques, pore-scale studies bring new information on the characterisation of the microstructure evolution. While it is readily conceivable that observations at the pore scale would help in an easier way to fill the gap between microscopic and reservoir scales, they actually call some 


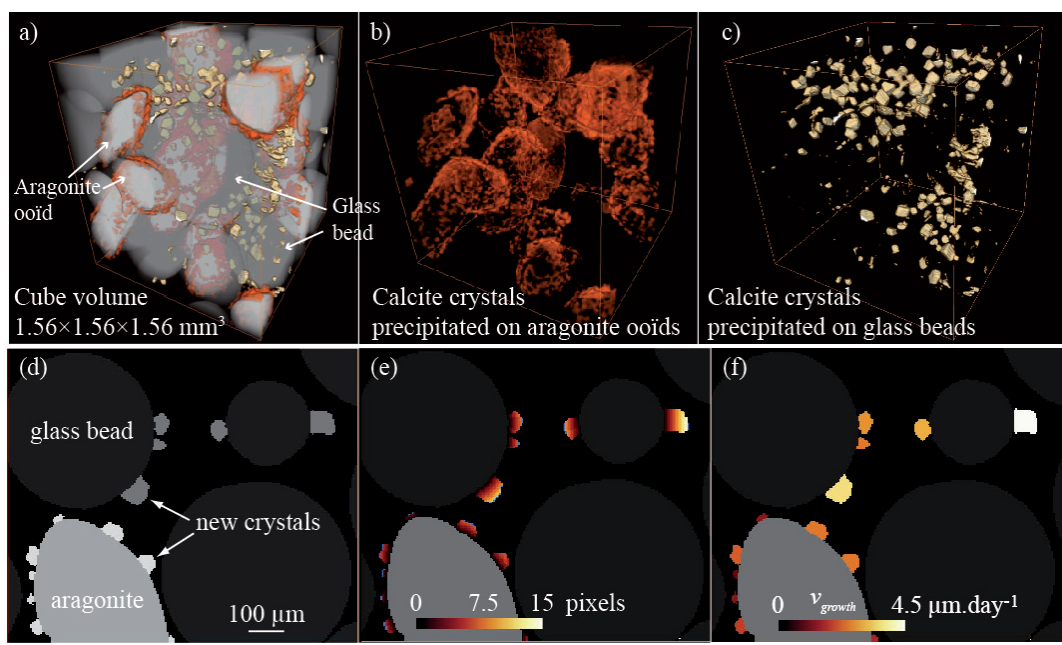

Fig. 10 Evidence of crystal growth heterogeneity in a porous sandstone analogue during calcite precipitation. (a) Identification of newly formed calcite crystals on (b) aragonite ooïds and (c) glass beads evidences the dependence of the growth rate, density and shape of newly formed crystals on the substrate (see [112] for more details about the experiment); (d) 2D cross-section derived from the 3D volume in (a); (e) measurement of the crystal length normal to the substrate and (f) derived calcite growth rate

Reprinted in part with permission from [102], Copyright ACS 2017; and with permission from [112], Copyright Elsevier 2016.

paradigms into question and bring new challenges for modelling of reactive transport at the continuum scale. The most striking example is certainly the development of micro-porous altered layers in an argillaceous limestone that leads to a decrease of permeability despite the increase of porosity, as evidenced in [107] and other following studies $[44,83,87]$. At the continuum scale, the relationship between the different physical parameters describing the rock often relies on empirical models established at the REV scale. In the present cases, the empirical models used to describe porosity-permeability relationship are typically unable to account for these observations, which actually may also involve mechanical deformation of the altered matrix and release or migration of fine particles through the porous network. Upscaling of the flow and transport properties should benefit from these pore-scale observations.

The standard strategy for upscaling physical processes from the pore to the reservoir scale (see Figure 11) involves a cascade of description levels nested within each other [154]. A first important challenge is purely technological and concerns the development of imaging and computing capabilities that reach the size of a REV. The continuous improvements both in imaging devices and analysis, and in High-Performance Computing gives a glimpse of larger and larger sample sizes in the coming years. The recent introduction of machine learning tools offers a decrease in computational time for geochemical equilibrium calculations or for upscaling porosity-permeability relationship $[75,90,35]$. The biggest challenge, however, is conceptual. For example, the exponential decay laws that estimate the accessible reactive surface area according to hydrodynamic conditions have been proposed 
for mono-mineral rocks only $[135,38,153]$ and the existence of universal constitutive relationships for complex rock texture is still an open question. More importantly, reactive processes including dissolution instabilities and ramified wormholing develop large heterogeneities that question the notion of REV for evolving microstructures [33]. It is commonly admitted that a potential method for upscaling should integrate different simulation approaches and data at different scales [23,21]. Multi-scale imaging and modelling such as the micro-continuum approaches discussed in this paper are promising ways to handle the complex heterogeneity and the wide range of spatial scales that exists, starting from sample size below $10^{-5}-10^{-6} \mathrm{~m}$.

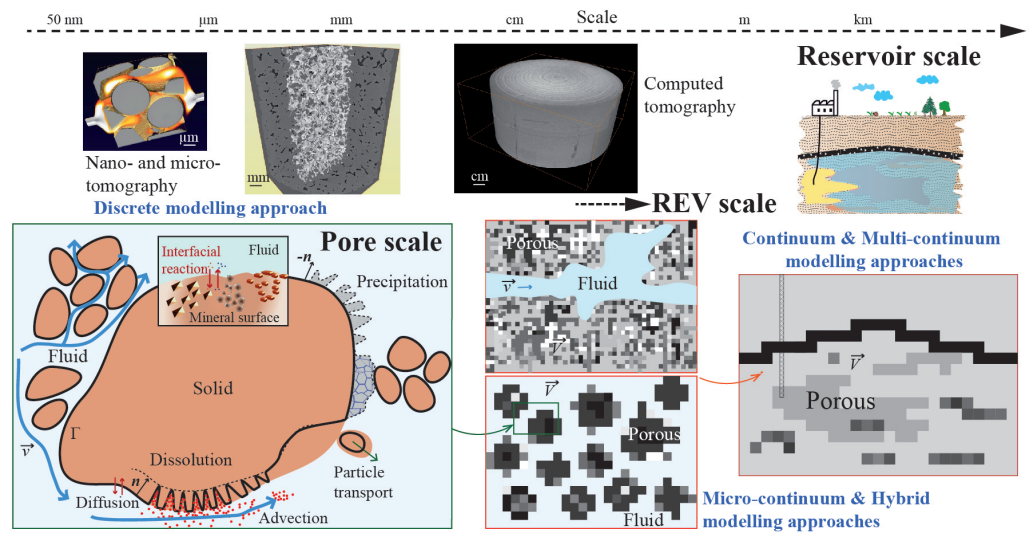

Fig. 11 Integration of approaches for reactive transport upscaling from pore to reservoir scale.

\subsection{Rock texture considerations}

XMT has made possible visualization of pore-scale structures in rocks with a large panel of mineralogy, chemistry, textures and fabrics. An increasing number of wellconstrained experiments coupled with pore-scale studies highlights, through mineralogical, chemical and physical heterogeneities, the role played by these complex structures on both flow and transport, as well as on reactive transport dynamics [100]. If rock anisotropic properties, i.e., permeability anisotropy, have long been pointed to favour the development of instabilities along preferential directions at reservoir scale [116], it is logical that structural heterogeneity at the pore scale triggers the same type of instabilities. In this way, core samples with heterogeneous pore structure promote unstable dissolution fronts compared to more homogeneous pore networks $[130,91]$. The development of heterogeneous transport, associating advective-dominant flowpaths to adjacent areas of stagnant fluid dominated by diffusive transport also favors the appearance of non-local equilibrium at the pore scale. For instance, precipitation can be observed locally in dead-end pores although the percolating fluid remains globally highly undersaturated [7]. In addition, it is worth noting that a homogeneous pore space cannot guarantee the non-development of instabilities [102]. In particular, new structural heterogeneity can emerge in rocks with 
different mineral reactivity $[107,5,44,51]$. The most streaking example is certainly the argillaceous limestone sample mentioned in Figure 3, where a new structure, i.e., the micro-porous altered layer of silicates, grows at the interface while the carbonate phase keeps dissolving. In this example, orders of difference in the dissolution kinetic rate between silicates and carbonates drive the formation of new structural heterogeneities that deeply reorganise flow and transport. The detachment and migration of fine particles also result from differential dissolution between minerals in the rock matrix. However, new structural heterogeneity can also emerge as well in mono-mineralic rocks, e.g., through the reorganisation of flowpaths and transport at the grain boundaries of two types of calcite with different specific surface, reactivity and diffusivity [106]. The intrinsic reactivity of some minerals can also be highly sensitive to micro-structural modifications at the fluid mineral interface [102]. To summarize, characterisation and consideration of rock texture evolution at the pore scale offer an unprecedented opportunity to give more physico-chemical basis on phenomena that were ignored or poorly-understood until the advent of pore-scale studies. Hopefully, integration of more realistic thermo-kinetics formulation basis in models of reactive transport at the pore scale $[48,92,134,75]$ will permit to bridge the gap to larger scales.

Acknowledgements We thanks Hannah Menke and the six anonymous reviewers for their constructive comments. C.N. acknowledges funding from CNRS trough the project INSU Tellus CESSUR GEOCARB. C.S. acknowledges funding from the French Agency for Research (Agence Nationale de la Recherche, ANR) through the labex Voltaire ANR-10-LABX-100-01 and the FraMatI project under contract ANR-19-CE05-0002. C.S. has also received financial support from the CNRS through the MITI interdisciplinary programs. The authors benefited from the use of the cluster at the Centre de Calcul Scientifique en région Centre-Val de Loire.

\section{References}

1. Abdoulghafour, H., Luquot, L., Gouze, P.: Characterization of the mechanisms controlling the permeability changes of fractured cements flowed through by $\mathrm{CO}_{2}$-rich brine. Environmental Science \& Technology 47(18), 10332-10338 (2013). DOI 10.1021/es401317c

2. Ajo-Franklin, J., Voltolini, M., Molins, S., Yang, L.: Coupled processes in a fractured reactive system: A dolomite dissolution study with relevance to gcs caprock integrity. In: Caprock Integrity in Geological Storage: Hydrogeochemical and Hydrogeomechanical Processes and their Impact on Storage Security. Wiley Publishing: New York (2018)

3. Akmal Butt, M., Maragos, P.: Optimum design of chamfer distance transforms. Image Processing, IEEE Transactions 7(10), 1477-1484 (1998). DOI 10.1109/83.718487

4. Al-Khulaifi, Y., Lin, Q., Blunt, M.J., Bijeljic, B.: Reservoir-condition pore-scale imaging of dolomite reaction with supercritical $\mathrm{CO} 2$ acidified brine: Effect of pore-structure on reaction rate using velocity distribution analysis. International Journal of Greenhouse Gas Control 68, 99-111 (2018). DOI https://doi.org/10.1016/j.ijggc.2017.11.011

5. Al-Khulaifi, Y., Lin, Q., Blunt, M.J., Bijeljic, B.: Pore-scale dissolution by $\mathrm{CO} 2$ saturated brine in a multimineral carbonate at reservoir conditions: Impact of physical and chemical heterogeneity. Water Resources Research 55(4), 3171-3193 (2019). DOI https://doi.org/10.1029/2018WR024137. URL https://agupubs.onlinelibrary.wiley.com/doi/abs/10.1029/2018WR024137. _eprint: https://agupubs.onlinelibrary.wiley.com/doi/pdf/10.1029/2018WR024137

6. Allen, S.M., Cahn, J.W.: A microscopic theory for antiphase boundary motion and its application to antiphase domain coarsening. Acta Metallurgica 27, 1085-1095 (1979). DOI 10.1016/0001-6160(79)90196-2

7. Andreani, M., Luquot, L., Gouze, P., Godard, M., Hoise, E., Gibert, B.: Experimental study of carbon sequestration reactions controlled by the percolation of $\mathrm{CO} 2$-rich brine 
through peridotites. Environmental Science \& Technology 43(4), 1226-1231 (2009-0215). DOI $10.1021 /$ es 8018429

8. Andrew, M.: A quantified study of segmentation techniques on synthetic geological xrm and fib-sem images. Computational Geosciences 22(6), 1503-1512 (2018). DOI 10.1007/ s10596-018-9768-y

9. Andrä, H., Combaret, N., Dvorkin, J., Glatt, E., Han, J., Kabel, M., Keehm, Y., Krzikalla, F., Lee, M., Madonna, C., Marsh, M., Mukerji, T., Saenger, E.H., Sain, R., Saxena, N., Ricker, S., Wiegmann, A., Zhan, X.: Digital rock physics benchmarks-part i: Imaging and segmentation. Computers \& Geosciences 50, 25-32 (2013-01). DOI 10.1016/j.cageo. 2012.09.005

10. Andrä, H., Combaret, N., Dvorkin, J., Glatt, E., Han, J., Kabel, M., Keehm, Y., Krzikalla, F., Lee, M., Madonna, C., Marsh, M., Mukerji, T., Saenger, E.H., Sain, R., Saxena, N., Ricker, S., Wiegmann, A., Zhan, X.: Digital rock physics benchmarks-part II: Computing effective properties. Computers \& Geosciences 50, 33-43 (2013-01). DOI 10.1016/j.cageo. 2012.09.008

11. Angot, P., Bruneau, C.H., Fabrie, P.: A penalization method to take into account obstacles in incompressible viscous flows. Numerische Mathematik 81(4), 497-520 (1999)

12. Apourvari, S.N., Arns, C.H.: An assessment of the influence of micro-porosity for effective permeability using local flux analysis on tomographic images. International Petroleum Technology Conference, 19-22 January, Doha, Qatar (2014)

13. Armstrong, R.T., Ott, H., Georgiadis, A., Rücker, M., Schwing, A., Berg, S.: Subsecond pore-scale displacement processes and relaxation dynamics in multiphase flow. Water Resources Research 50(12), 9162-9176 (2014). DOI 10.1002/2014wr015858

14. Arns, C., Bauget, F., Limaye, A., Sakellariou, A., Senden, T., Sheppard, A., Sok, R., Pinczewski, W., Bakke, S., Berge, L., Oeren, P.E., Knackstedt, M.: Pore-scale characterization of carbonates using x-ray microtomography. SPE Journal 10(4), 475-484 (2005)

15. Arvidson, R.S., Beig, M.S., Lüttge, A.: Single-crystal plagioclase feldspar dissolution rates measured by vertical scanning interferometry. American Mineralogist 89(1), 51-56 (2004-01)

16. Auriault, J.L.: On the domain of validity of brinkman's equation. Transport in porous media 79(2), 215-223 (2009)

17. Battiato, I., Tartakovsky, D.M., Tartakovsky, A.M., Scheibe, T.D.: Hybrid models of reactive transport in porous and fractured media. Advances in Water Resources 34(9), 1140-1150 (2011)

18. Bear, J.: Dynamics of Fluids in Porous Media. Dover Civil and Mechanical Engineering Series. Dover (1988). URL https://books.google.fr/books?id=lurrmlFGhTEC

19. Beavers, G.S., Joseph, D.D.: Boundary conditions at a naturally permeable wall. Journal of Fluid Mechanics 30, 197-207 (1967). DOI 10.1017/S0022112067001375

20. Berg, C.F., Lopez, O., Berland, H.: Industrial applications of digital rock technology. Journal of Petroleum Science and Engineering 157, 131 - 147 (2017). DOI https: //doi.org/10.1016/j.petrol.2017.06.074. URL http://www.sciencedirect.com/science/ article/pii/S0920410517305600

21. Berkowitz, B., Dror, I., Hansen, S.K., Scher, H.: Measurements and models of reactive transport in geological media. Reviews of Geophysics pp. n/a-n/a (2016). DOI 10.1002/ 2016rg000524

22. Bernard, D.: 3d quantification of pore scale geometrical changes using synchrotron computed microtomography. Oil \& Gas Science and Technology 60(5), 747-762 (2005)

23. Blunt, M.J., Bijeljic, B., Dong, H., Gharbi, O., Iglauer, S., Mostaghimi, P., Paluszny, A., Pentland, C.: Pore-scale imaging and modelling. Advances in Water Resources 51, 197-216 (2013-01). DOI 10.1016/j.advwatres.2012.03.003

24. Brackbill, J., Kothe, D., Zemach, C.: A continuum method for modeling surface tension. Journal of Computational Physics 100(2), 335 - 354 (1992). DOI http://dx.doi.org/10. 1016/0021-9991(92)90240-Y. URL http://www.sciencedirect.com/science/article/ pii/002199919290240Y

25. Braissant, O., Cailleau, G., Dupraz, C., Verrecchia, A.P.: Bacterially induced mineralization of calcium carbonate in terrestrial environments: The role of exopolysaccharides and amino acids. Journal of Sedimentary Research 73(3), 485-490 (2003)

26. Bringedal, C., Kumar, K.: Effective behavior near clogging in upscaled equations for nonisothermal reactive porous media flow. Transport in Porous Media 120, 553-577 (2017). DOI $10.1007 / \mathrm{s} 11242-017-0940-y$ 
27. Brinkman, H.C.: A calculation of the viscous force exerted by a flowing fluid on a dense swarm of particles. Appl. Sci. Res. A1, 27-34 (1947)

28. Burlion, N., Bernard, D., Chen, D.: X-ray microtomography: Application to microstructure analysis of a cementitious material during leaching process. Cement and Concrete Research 36, 346-357 (2006). URL http://www.sciencedirect.com/science/article/ B6TWG-4GP7PCP-1/2/7bf7a67b79c80cda9f6873eac5253fd7. 2

29. Butler, I., Fusseis, F., Cartwright-Taylor, A., Flynn, M.: Mjölnir: a miniature triaxial rock deformation apparatus for $4 \mathrm{~d}$ synchrotron x-ray microtomography. Journal of Synchrotron Radiation 27(6), 1681-1687 (2020). DOI 10.1107/S160057752001173X. URL https://doi.org/10.1107/S160057752001173X

30. Cahn, J.W., Hilliard, J.E.: Free energy of a nonuniform system. i. interfacial free energy. The Journal of Chemical Physics 28(2), 258-267 (1958). DOI http://dx.doi.org/10.1063/ 1.1744102. URL http://scitation.aip.org/content/aip/journal/jcp/28/2/10.1063/ 1.1744102

31. Caltagirone, J.P.: Physique des écoulements continus. Springer (2013)

32. Chen, L., Kang, Q., Viswanathan, H.S., Tao, W.Q.: Pore-scale study of dissolutioninduced changes in hydrologic properties of rocks with binary minerals. Water Resources Research 50(12), 9343-9365 (2014). DOI 10.1002/2014WR015646. URL http: //dx.doi.org/10.1002/2014WR015646

33. Daccord, G., Lenormand, R.: Fractal patterns from chemical dissolution. Nature 325(6099), 41-43 (1987)

34. Daval, D., Sissmann, O., Menguy, N., Saldi, G.D., Guyot, F., Martinez, I., Corvisier, J., Garcia, B., Machouk, I., Knauss, K.G., Hellmann, R.: Influence of amorphous silica layer formation on the dissolution rate of olivine at 90 degrees $\mathrm{c}$ and elevated $\mathrm{pCO}(2)$. Chemical Geology 284(1), 193-209 (2011-05-09). DOI 10.1016/j.chemgeo.2011.02.021

35. De Lucia, M., Kühn, M.: DecTree v1.0 - chemistry speedup in reactive transport simulations: purely data-driven and physics-based surrogates. Geoscientific Model Development Discussions 2021, 1-26 (2021). DOI 10.5194/gmd-2020-445. URL https: //gmd.copernicus . org/preprints/gmd-2020-445/

36. De Yoreo, J.J., Vekilov, P.G.: Principles of crystal nucleation and growth. In: P.M. Dove, J.J. DeYoreo, S. Weiner (eds.) Biomineralization, Reviews in Mineralogy $\& 5$ Geochemistry, vol. 54, pp. 57-93. Mineralogical Society of America (2003)

37. Deng, H., Molins, S., Steefel, C., DePaolo, D., Voltolini, M., Yang, L., Ajo-Franklin, J.: A $2.5 \mathrm{~d}$ reactive transport model for fracture alteration simulation. Environmental Science \& Technology 50(14), 7564-7571 (2016). DOI 10.1021/acs.est.6b02184

38. Deng, H., Molins, S., Trebotich, D., Steefel, C., DePaolo, D.: Pore-scale numerical investigation of the impacts of surface roughness: Upscaling of reaction rates in rough fractures. Geochimica et Cosmochimica Acta 239, 374-389 (2018)

39. Deng, H., Voltolini, M., Molins, S., Steefel, C., DePaolo, D., Ajo-Franklin, J., Yang, L.: Alteration and erosion of rock matrix bordering a carbonate-rich shale fracture. Environmental Science \& Technology 51(15), 8861-8868 (2017). DOI 10.1021/acs.est.7b02063

40. Dou, Q., Yu, L., Chen, H., Jin, Y., Yang, X., Qin, J., Heng, P.A.: 3D deeply supervised network for automated segmentation of volumetric medical images. Medical Image Analysis 41, 40-54 (2017). DOI \{10.1016/j.media.2017.05.001\}. 19th Int Conf on Med Image Comp and Comp-Assisted Intervent (MICCAI) / Int Workshop on Med Comp Vis (MCV) / 3rd Int Workshop on Bayesian and Graph Models for Biomedical Imaging (BAMBI), Athens, GREECE, OCT 21, 2016

41. Dutka, F., Starchenko, V., Osselin, F., Magni, S., Szymczak, P., Ladd, A.J.: Timedependent shapes of a dissolving mineral grain: Comparisons of simulations with microfluidic experiments. Chemical Geology 540, 119459 (2020). DOI https://doi.org/10. 1016/j.chemgeo.2019.119459. URL http://www.sciencedirect.com/science/article/ pii/S0009254119305881

42. Edelsbrunner, H., Ablowitz, M.J., Davis, S.H., Hinch, E.J., Iserles, A., Ockendon, J., Olver, P.J.: Geometry and Topology for Mesh Generation (Cambridge Monographs on Applied and Computational Mathematics). Cambridge University Press, USA (2006)

43. Elkhoury, J.E., Detwiler, R.L., Ameli, P.: Can a fractured caprock self-heal? Earth and Planetary Science Letters 417, 99-106 (2015). DOI http://dx.doi.org/10.1016/j.epsl. 2015.02.010

44. Ellis, B.R., Fitts, J.P., Bromhal, G.S., McIntyre, D.L., Tappero, R., Peters, C.A.: Dissolution-driven permeability reduction of a fractured carbonate caprock. Environmental Engineering Science 30(4), 187-193 (2013-04). DOI 10.1089/ees.2012.0337 
45. Faris, A., Maes, J., Menke, H.: An investigation into the upscaling of mineral dissolution from the pore to the core scale. In: Conference Proceedings, ECMOR XVII, vol. 2020, pp. 1-15 (2020). DOI https://doi.org/10.3997/2214-4609.202035250. URL https: //www. earthdoc.org/content/papers/10.3997/2214-4609.202035250. Publisher: European Association of Geoscientists \&amp; Engineers

46. Fernandez-Martinez, A., Hu, Y., Lee, B., Jun, Y.S., Waychunas, G.A.: In situ determination of interfacial energies between heterogeneously nucleated CaCO3 and quartz substrates: Thermodynamics of CO2 mineral trapping. Environmental Science \& Technology 47(1), 102-109 (2013-01-02). DOI 10.1021/es3014826

47. Fischer, C., Arvidson, R.S., Lüttge, A.: How predictable are dissolution rates of crystalline material? Geochimica Et Cosmochimica Acta 98, 177-185 (2012). Times Cited: 23

48. Flukiger, F., Bernard, D.: A new numerical model for pore scale dissolution of calcite due to $\mathrm{CO}_{2}$ saturated water flow in real rocks: Principles and first results. Chemical Geology 265(1), 171-180 (2009)

49. Fredrich, J.T., Digiovanni, A.A., Noble, D.R.: Predicting macroscopic transport properties using microscopic image data. Journal of Geophysical Research-Solid Earth 111(B3), B03201, doi:10.1029/2005JB003774 (2006). B03201

50. Fusseis, F., Schrank, C., Liu, J., Karrech, A., Llana-Funez, S., Xiao, X., Regenauer-Lieb, K.: Pore formation during dehydration of a polycrystalline gypsum sample observed and quantified in a time-series synchrotron x-ray micro-tomography experiment. Solid Earth 3(1), 71-86 (2012). DOI 10.5194/se-3-71-2012

51. Garcia-Rios, M., Luquot, L., Soler, J.M., Cama, J.: The role of mineral heterogeneity on the hydrogeochemical response of two fractured reservoir rocks in contact with dissolved CO2. Applied Geochemistry (2017). DOI https://doi.org/10.1016/j.apgeochem.2017.06. 008

52. Garing, C., de Chalendar, J.A., Voltolini, M., Ajo-Franklin, J.B., Benson, S.M.: Pore-scale capillary pressure analysis using multi-scale x-ray micromotography. Advances in Water Resources 104, 223-241 (2017). DOI https://doi.org/10.1016/j.advwatres.2017.04.006

53. Godinho, J.R.A., Gerke, K.M., Stack, A.G., Lee, P.D.: The dynamic nature of crystal growth in pores. Scientific Reports 6 (2016-09). DOI 3308610.1038/srep33086

54. Godinho, J.R.A., Withers, P.J.: Time-lapse 3d imaging of calcite precipitation in a microporous column. Geochimica Et Cosmochimica Acta 222, 156-170 (2018)

55. Golfier, F., Zarcone, C., Bazin, B., Lenormand, R., Lasseux, D., Quintard, M.: On the ability of a darcy-scale model to capture wormhole formation during the dissolution of a porous medium. Journal of fluid Mechanics 457, 213-254 (2002)

56. Gonzales, R.C., Woods, R.E.: Digital image processing. Addison-Wesley Publishing Compagny, Reading, Massachusetts (1992)

57. Gouze, P., Noiriel, C., Bruderer, C., Loggia, D., Leprovost, R.: X-ray tomography characterisation of fracture surfaces during dissolution. Geophysical Research Letters 30, 1267, doi:10.1029/2002/GL016755 (2003). 5

58. Gray, F., Anabaraonye, B., Shah, S., Boek, E., Crawshaw, J.: Chemical mechanisms of dissolution of calcite by hcl in porous media: Simulations and experiment. Advances in Water Resources 121, 369-387 (2018). DOI 10.1016/j.advwatres.2018.09.007

59. Gärttner, S., Frolkovic, P., Knabner, P., Ray, N.: Efficiency and accuracy of micro-macro modelsfor mineral dissolution. Water Resources Research 56(8), 1-23 (2020). DOI 10.1029/2020WR027585

60. Hilgers, C., Dilg-Gruschinski, K., Urai, J.L.: Microstructural evolution of syntaxial veins formed by advective flow. Geology 32(3), 261-264 (2004-03)

61. Hirt, C., Nichols, B.: Volume of fluid (vof) method for the dynamics of free boundaries. Journal of Computational Physics 39(1), 201 - 225 (1981). DOI http://dx. doi.org/10.1016/0021-9991(81)90145-5. URL http://www.sciencedirect.com/science/ article/pii/0021999181901455

62. Huang, H., Li, X.: Pore-scale simulation of coupled reactive transport and dissolution in fractures and porous media using the level set interface tracking method. Journal of Nanjing University (Natural Sciences) 47(3), 235-251 (2011). URL http://www.osti. gov/scitech/servlets/purl/1048897

63. Hébert, V., Garing, C., Luquot, L., Pezard, P.A., Gouze, P.: Multi-scale x-ray tomography analysis of carbonate porosity. In: S.M. Agar, S. Geiger (eds.) Fundamental Controls on Fluid Flow in Carbonates: Current Workflows to Emerging Technologies, vol. 409, pp. 61-79. Geological Society (2015) 
64. Iassonov, P., Gebrenegus, T., Tuller, M.: Segmentation of x-ray computed tomography images of porous materials: A crucial step for characterization and quantitative analysis of pore structures. Water Resources Research 45 (2009-09-24). DOI 10.1029/2009wr008087

65. Iglauer, S., Paluszny, A., Pentland, C.H., Blunt, M.J.: Residual $\mathrm{CO}_{2}$ imaged with $\mathrm{x}-$ ray micro-tomography. Geophysical Research Letters 38, L21403 (2011-11-10). DOI $10.1029 / 2011 \mathrm{gl} 1049680$

66. Kahl, W.A., Yuan, T., Bollermann, T., Bach, W., Fischer, C.: Crystal surface reactivity analysis using a combined approach of x-ray micro-computed tomography and vertical scanning interferometry. American Journal of Science 320(1), 27-52 (2020). DOI 10. $2475 / 01.2020 .03$

67. Kamrava, S., Tahmasebi, P., Sahimi, M.: Enhancing images of shale formations by a hybrid stochastic and deep learning algorithm. Neural Networks 118, 310-320 (2019). DOI https://doi.org/10.1016/j.neunet.2019.07.009. URL https://www.sciencedirect. com/science/article/pii/S0893608019301972

68. Kang, Q., Chen, L., Valocchi, A.J., Viswanathan, H.S.: Pore-scale study of dissolutioninduced changes in permeability and porosity of porous media. Journal of Hydrology $\mathbf{5 1 7}, 1049-1055$ (2014)

69. Kang, Q., Zhang, D., Chen, S.: Simulation of dissolution and precipitation in porous media. Journal of Geophysical Research: Solid Earth (1978-2012) 108(B10), 1-5 (2003)

70. Kang, Q., Zhang, D., Chen, S., He, X.: Lattice boltzmann simulation of chemical dissolution in porous media. Physical Review E 65(3), 036318 (2002)

71. Khadra, K., Angot, P., Parneix, S., Caltagirone, J.P.: Fictitious domain approach for numerical modelling of navier-stokes equations. International Journal for Numerical Methods in Fluids 34(8), 651-684 (2000). DOI 10.1002/1097-0363(20001230)34:8<651:: AID-FLD61)3.0.CO;2-D. URL http://dx.doi.org/10.1002/1097-0363(20001230)34: 8<651: :AID-FLD61>3.0.C0;2-D

72. Ladd, A.J.C., Yu, L., Szymczak, P.: Dissolution of a cylindrical disk in hele-shaw flow: a conformal-mapping approach. Journal of Fluid Mechanics 903(A46), 1-29 (2020). DOI $10.1017 / \mathrm{jfm} .2020 .609$

73. Landau, Lifshitz: Fluid mechanics. In: Course of Theoretical Physics, vol. 6, 2nd english edition edn. Elsevier (1987)

74. Landry, C.J., Karpyn, Z.T., Ayala, O.: Pore-scale lattice boltzmann modeling and 4d $\mathrm{x}$-ray computed microtomography imaging of fracture-matrix fluid transfer. Transport in Porous Media 103(3), 449-468 (2014-07). DOI 10.1007/s11242-014-0311-x

75. Leal, A.M.M., Kyas, S., Kulik, D.A., Saar, M.O.: Accelerating reactive transport modeling: On-demand machine learning algorithm for chemical equilibrium calculations. Transport in Porous Media 133(2), 161-204 (2020-06-01). DOI 10.1007/s11242-020-01412-1. URL https://doi.org/10.1007/s11242-020-01412-1

76. Li, X., Huang, H., Meakin, P.: Level set simulation of coupled advection-diffusion and pore structure evolution due to mineral precipitation in porous media. Water Resources Research 44(12) (2008)

77. Li, X., Huang, H., Meakin, P.: A three-dimensional level set simulation of coupled reactive transport and precipitation/dissolution. International Journal of Heat and Mass Transfer 53(13), 2908-2923 (2010)

78. Liu, M., Mostaghimi, P.: High-resolution pore-scale simulation of dissolution in porous media. Chemical Engineering Science 161, 360-369 (2017). DOI 10.1016/j.ces.2016.12. 064

79. Liu, X., Ormond, A., Bartko, K., Ying, L., Ortoleva, P.: A geochemical reaction-transport simulator for matrix acidizing analysis and design. Journal of Petroleum Science and Engineering 17(1), 181-196 (1997)

80. Liu, X., Ortoleva, P.: A general-purpose, geochemical reservoir simulator. In: SPE Annual Technical Conference and Exhibition. Society of Petroleum Engineers (1996)

81. Luhmann, A.J., Kong, X.Z., Tutolo, B.M., Garapati, N., Bagley, B.C., Saar, M.O., Seyfried, W.E.: Experimental dissolution of dolomite by $\mathrm{CO}_{2}$-charged brine at 100 degrees $\mathrm{c}$ and 150 bar: Evolution of porosity, permeability, and reactive surface area. Chemical Geology 380, 145-160 (2014-07-25). DOI 10.1016/j.chemgeo.2014.05.001

82. Luquot, L., Gouze, P.: Experimental determination of porosity and permeability changes induced by injection of $\mathrm{CO}_{2}$ into carbonate rocks. Chemical Geology 265(1), 148-159 (2009-07-15). DOI 10.1016/j.chemgeo.2009.03.028

83. Luquot, L., Roetting, T.S., Carrera, J.: Characterization of flow parameters and evidence of pore clogging during limestone dissolution experiments. Water Resources Research 50(8), 6305-6321 (2014-08). DOI 10.1002/2013wr015193 
84. Madonna, C., Quintal, B., Frehner, M., Almqvist, B., Tisato, N., Pistone, M., Marone, F., Saenger, E.: Synchrotron-based x-ray tomographic microscopy for rock physics investigations. Geophysics 78(1), D53-D64 (2018-06-19). DOI 10.1190/geo2012-0113.1

85. Maes, F., Collignon, A., Vandermeulen, D., Marchal, G., Suetens, P.: Multimodality image registration by maximization of mutual information. IEEE TRANSACTIONS ON MEDICAL IMAGING 16(2), 187-198 (1997). DOI $\{10.1109 / 42.563664\}$

86. Maire, E., Withers, P.J.: Quantitative x-ray tomography. International Materials Reviews 59(1), 1-43 (2014). DOI 10.1179/1743280413Y.0000000023

87. Mangane, P.O., Gouze, P., Luquot, L.: Permeability impairment of a limestone reservoir triggered by heterogeneous dissolution and particles migration during $\mathrm{CO}_{2}$-rich injection. Geophysical Research Letters 40(17), 4614-4619 (2013-09-16). DOI 10.1002/grl.50595

88. Marone, F., Schlepütz, C.M., Marti, S., Fusseis, F., Velásquez-Parra, A., Griffa, M., Jiménez-Martínez, J., Dobson, K.J., Stampanoni, M.: Time resolved in situ x-ray tomographic microscopy unraveling dynamic processes in geologic systems. Frontiers in Earth Science 7, 346 (2020). DOI 10.3389/feart.2019.00346. URL https://www.frontiersin. org/article/10.3389/feart.2019.00346

89. Marone, F., Studer, A., Billich, H., Sala, L., Stampanoni, M.: Towards on-the-fly data post-processing for real-time tomographic imaging at TOMCAT. Advanced Structural and Chemical Imaging 3(1), 1 (2017-01-03). DOI 10.1186/s40679-016-0035-9

90. Menke, H.P., Maes, J., Geiger, S.: Upscaling the porosity-permeability relationship of a microporous carbonate for darcy-scale flow with machine learning. Scientific Reports 11(1), 2625 (2021-01-29). DOI 10.1038/s41598-021-82029-2. URL https://doi.org/10. $1038 / \mathrm{s} 41598-021-82029-2$

91. Menke, H.P., Reynolds, C.A., Andrew, M.G., Pereira Nunes, J.P., Bijeljic, B., Blunt, M.J.: 4d multi-scale imaging of reactive flow in carbonates: Assessing the impact of heterogeneity on dissolution regimes using streamlines at multiple length scales. Chemical Geology 481, 27-37 (2018). DOI https://doi.org/10.1016/j.chemgeo.2018.01.016

92. Molins, S.: Reactive Interfaces in Direct Numerical Simulation of Pore-Scale Processes. Reviews in Mineralogy \& Geochemistry 80(1), 461-481 (2015). DOI 10.2138/rmg.2015. 80.14. URL https://doi.org/10.2138/rmg.2015.80.14

93. Molins, S., Soulaine, C., Prasianakis, N., Abbasi, A., Poncet, P., Ladd, A., Starchenko, V., Roman, S., Trebotich, D., Tchelepi, H., Steefel, C.: Simulation of mineral dissolution at the pore scale with evolving fluid-solid interfaces: Review of approaches and benchmark problem set. Computational Geosciences pp. 1-34 (2020)

94. Molins, S., Trebotich, D., Arora, B., Steefel, C.I., Deng, H.: Multi-scale model of reactive transport in fractured media: diffusion limitations on rates. Transport in Porous Media 128(2), 701-721 (2019)

95. Molins, S., Trebotich, D., Miller, G.H., Steefel, C.I.: Mineralogical and transport controls on the evolution of porous media texture using direct numerical simulation. Water Resources Research 53(5), 3645-3661 (2017)

96. Molins, S., Trebotich, D., Steefel, C.I., Shen, C.: An investigation of the effect of pore scale flow on average geochemical reaction rates using direct numerical simulation. Water Resources Research 48 (2012). DOI 10.1029/2011wr011404

97. Molins, S., Trebotich, D., Yang, L., Ajo-Franklin, J.B., Ligocki, T.J., Shen, C., Steefel, C.I.: Pore-scale controls on calcite dissolution rates from flow-through laboratory and numerical experiments. Environmental science \& technology 48(13), 7453-7460 (2014)

98. Neale, G., Nader, W.: Practical significance of brinkman's extension of darcy's law: coupled parallel flows within a channel and a bounding porous medium. The Canadian Journal of Chemical Engineering 52(4), 475-478 (1974)

99. Niu, Y., Mostaghimi, P., Shabaninejad, M., Swietojanski, P., Armstrong, R.T.: Digital rock segmentation for petrophysical analysis with reduced user bias using convolutional neural networks. Water Resources Research 56(2), e2019WR026597 (2020). DOI https://doi.org/10.1029/2019WR026597. URL https://agupubs.onlinelibrary.wiley.com/doi/abs/10.1029/2019WR026597. _eprint: https://agupubs.onlinelibrary.wiley.com/doi/pdf/10.1029/2019WR026597

100. Noiriel, C.: Resolving time-dependent evolution of pore scale structure, permeability and reactivity using x-ray microtomography. In: C.I. Steefel, E. Emmanuel, L. Anovitz (eds.) Pore Scale Geochemical Processes. Reviews in Mineralogy \& Geochemistry, vol. 80, pp. 247-286. Mineralogical Society of America (2015)

101. Noiriel, C., Bernard, D., Gouze, P., Thibaut, X.: Hydraulic properties and microgeometry evolution in the course of limestone dissolution by co2-enriched water. Oil \& Gas Science and Technology 60(1), 177-192 (2005) 
102. Noiriel, C., Daval, D.: Pore-scale geochemical reactivity associated with co2 storage: New frontiers at the fluid-solid interface. Accounts of Chemical Research 50(4), 759-768 (2017). Doi: 10.1021/acs.accounts.7b00019

103. Noiriel, C., Deng, H.: Evolution of planar fractures in limestone: the role of flow rate, mineral heterogeneity and local transport processes. Chemical Geology 497, 100-114 (2018)

104. Noiriel, C., Gouze, P., Bernard, D.: Investigation of porosity and permeability effects from microstructure changes during limestone dissolution. Geophysical Research Letters 31(24), L24603, doi:10.1029/2004GL021572 (2004)

105. Noiriel, C., Gouze, P., Made, B.: 3d analysis of geometry and flow changes in a limestone fracture during dissolution. Journal of Hydrology 486, 211-223 (2013-04). DOI 10.1016/ j.jhydrol.2013.01.035

106. Noiriel, C., Luquot, L., Madé, B., Raimbault, L., Gouze, P., van der Lee, J.: Changes in reactive surface area during limestone dissolution: An experimental and modelling study. Chemical Geology 265(1-2), 160 - 170 (2009). DOI http://dx.doi.org/10. 1016/j.chemgeo.2009.01.032. URL http://www.sciencedirect.com/science/article/ pii/S0009254109000643. \{CO2\} geological storage: Integrating geochemical, hydrodynamical, mechanical and biological processes from the pore to the reservoir scale

107. Noiriel, C., Madé, B., Gouze, P.: Impact of coating development on the hydraulic and transport properties in argillaceous limestone fracture. Water resources research 43(9), $1-16(2007)$

108. Noiriel, C., Oursin, M., Daval, D.: Examination of crystal dissolution in 3d: a way to reconcile dissolution rates in the laboratory? Geochimica et Cosmochimica Acta 3, 1-25 (2020). DOI https://doi.org/10.1016/j.gca.2020.01.003. URL http://www. sciencedirect.com/science/article/pii/S0016703720300041

109. Noiriel, C., Oursin, M., Saldi, G., Haberthür, D.: Direct determination of dissolution rates at crystal surfaces using 3d x-ray microtomography. ACS Earth and Space Chemistry 3(1), 100-108 (2019). DOI 10.1021/acsearthspacechem.8b00143

110. Noiriel, C., Seigneur, N., Le Guern, P., Lagneau, V.: Geometry and mineral heterogeneity controls on precipitation in fractures: an x-ray micro-tomography and reactive transport modeling study. Advances in Water Resources xx, xx (2021). DOI http://dx.doi.org/10. 1016/j.advwatres.2021.103916

111. Noiriel, C., Steefel, C.I., Yang, L., Ajo-Franklin, J.: Upscaling calcium carbonate precipitation rates from pore to continuum scale. Chemical Geology 318-319, 60-74 (2012)

112. Noiriel, C., Steefel, C.I., Yang, L., Bernard, D.: Effects of pore-scale heterogeneous precipitation on permeability and flow. Advances in Water Resources 95, 125-137 (2016). DOI http://dx.doi.org/10.1016/j.advwatres.2015.11.013

113. Ochoa-Tapia, J.A., Whitaker, S.: Momentum transfer at the boundary between a porous medium and a homogeneous fluid: I. theoretical development. International Journal of Heat and Mass Transfer 38(14), 2635-2646 (1995)

114. Oltéan, C., Golfier, F., Buès, M.A.: Numerical and experimental investigation of buoyancy-driven dissolution in vertical fracture. Journal of Geophysical Research: Solid Earth 118(5), 2038-2048 (2013)

115. Ormond, A., Ortoleva, P.: Numerical modeling of reaction-induced cavities in a porous rock. Journal of Geophysical Research: Solid Earth 105(B7), 16737-16747 (2000)

116. Ortoleva, P.: Geochemical self-organization. In: Geochemical self-organization, Oxford monographs on geology and geophysics, vol. 23. Oxford university press (1994)

117. Pilotti, M., Succi, S., Menduni, G.: Energy dissipation and permeability in porous media. Europhysics Letters 60(1), 72-78 (2002)

118. Pitas, I.: Digital image processing algorithms and applications. Wiley (2000)

119. Poonoosamy, J., Soulaine, C., Burmeister, A., Deissmann, G., Bosbach, D., Roman, S.: Microfluidic flow-through reactor and 3d raman imaging for in situ assessment of mineral reactivity in porous and fractured porous media. Lab-on-a-Chip 20, 2562-2571 (2020). DOI 10.1039/d0lc00360c

120. Prasianakis, N.I., Gatschet, M., Abbasi, A., Churakov, S.V.: Upscaling strategies of porosity-permeability correlations in reacting environments from pore-scale simulations. Geofluids 2018, 1-8 (2018). DOI 10.1155/2018/9260603

121. Putnis, A., Mauthe, G.: The effect of pore size on cementation in porous rocks. Geofluids 1(1), 37-41 (2001). DOI 10.1046/j.1468-8123.2001.11001.x

122. Rajyaguru, A., L'Hôpital, E., Savoye, S., Wittebroodt, C., Bildstein, O., Arnoux, P., Detilleux, V., Fatnassi, I., Gouze, P., Lagneau, V.: Experimental characterization of coupled 
diffusion reaction mechanisms in low permeability chalk. Chemical Geology 503, 29-39 (2018). DOI https://doi.org/10.1016/j.chemgeo.2018.10.016

123. Ray, N., Oberlander, J., Frolkovic, P.: Numerical investigation of a fully coupled micromacro model for mineral dissolution and precipitation. Computational Geosciences 23, 1173-1192 (2019). DOI 10.1007/s10596-019-09876-x

124. Renard, F., Cordonnier, B., Dysthe, D.K., Boller, E., Tafforeau, P., Rack, A.: A deformation rig for synchrotron microtomography studies of geomaterials under conditions down to $10 \mathrm{~km}$ depth in the earth. Journal of Synchrotron Radiation 23(4), 1030-1034 (2016). DOI doi:10.1107/S1600577516008730

125. Renard, F., McBeck, J., Cordonnier, B., Zheng, X., Sanchez, J.R., Kobchenko, M., Noiriel, C., Zhu, W., Meakin, P., Fusseis, F., Dysthe, D.K.: Dynamic in situ three-dimensional imaging and digital volume correlation reveal strain localization and fracture coalescence in sandstone. Pure and Applied Geophysics (2018). DOI 10.1007/s00024-018-2003-x

126. Russ, J.C.: The Image Processing Handbook, Sixth Edition. CRC Press (2011)

127. Scheibe, T.D., Perkins, W.A., Richmond, M.C., McKinley, M.I., Romero-Gomez, P.D.J., Oostrom, M., Wietsma, T.W., Serkowski, J.A., Zachara, J.M.: Pore-scale and multiscale numerical simulation of flow and transport in a laboratory-scale column. Water Resources Research 51(2), 1023-1035 (2015). DOI 10.1002/2014WR015959. URL http://dx.doi. org/10.1002/2014WR015959

128. Seigneur, N., Mayer, K.U., Steefel, C.I.: Reactive transport in evolving porous media. Reviews in Mineralogy and Geochemistry 85(1), 197-238 (2019). DOI 10.2138/rmg. 2019.85.7

129. Sethian, J.: Level Set Methods and Fast Marching Methods: Evolving Interfaces in Computational Geometry, Fluid Mechanics, Computer Vision and Materials Sciences. Cambridge University Press,2nd ed. (1999)

130. Smith, M.M., Sholokhova, Y., Hao, Y., Carroll, S.A.: $\mathrm{CO}_{2}$-induced dissolution of low permeability carbonates. part i: Characterization and experiments. Advances in Water Resources 62, 370-387 (2013-12). DOI 10.1016/j.advwatres.2013.09.008

131. Soulaine, C., Creux, P., Tchelepi, H.A.: Micro-continuum framework for pore-scale multiphase fluid transport in shale formations. Transport in Porous Media 127, 85-112 (2019)

132. Soulaine, C., Gjetvaj, F., Garing, C., Roman, S., Russian, A., Gouze, P., Tchelepi, H.: The impact of sub-resolution porosity of x-ray microtomography images on the permeability. Transport in Porous Media 113(1), 227-243 (2016). DOI 10.1007/s11242-016-0690-2

133. Soulaine, C., Maes, J., Roman, S.: Computational microfluidics for geosciences. Frontiers in Water (2021). DOI 10.3389/frwa.2021.643714

134. Soulaine, C., Pavuluri, S., Claret, F., Tournassat, C.: porousMedia4Foam: Multi-scale open-source platform for hydro-geochemical simulations with OpenFOAM. Earth and Space Science Open Archive (ESSOAr) preprint (2021). DOI 10.1002/essoar.10505772.1

135. Soulaine, C., Roman, S., Kovscek, A., Tchelepi, H.A.: Mineral dissolution and wormholing from a pore-scale perspective. Journal of Fluid Mechanics 827, 457-483 (2017)

136. Soulaine, C., Roman, S., Kovscek, A., Tchelepi, H.A.: Pore-scale modelling of multiphase reactive flow. Application to mineral dissolution with production of $\mathrm{CO}_{2}$. Journal of Fluid Mechanics 855, 616-645 (2018). DOI 10.1017/jfm.2018.655

137. Soulaine, C., Tchelepi, H.A.: Micro-continuum approach for pore-scale simulation of subsurface processes. Transport In Porous Media 113, 431-456 (2016). DOI 10.1007/ s11242-016-0701-3

138. Spanne, P., Thovert, J., Jacquin, C., Lindquist, W., Jones, K., Adler, P.: Synchrotron computed microtomography of porous media: topology and transports. Physical Review Letters 73(14), 2001 (1994)

139. Starchenko, V., Ladd, A.J.C.: The development of wormholes in laboratory-scale fractures: Perspectives from three-dimensional simulations. Water Resources Research 54, 7946-7959 (2018). DOI 10.1029/2018wr022948

140. Starchenko, V., Marra, C.J., Ladd, A.J.: Three-dimensional simulations of fracture dissolution. Journal of Geophysical Research: Solid Earth 121, 6421-6444 (2016). DOI 10.1002/2016JB013321

141. Steefel, C.I., Beckingham, L.E., Landrot, G.: Micro-continuum approaches for modeling pore-scale geochemical processes. Rev Mineral Geochem 80, 217-246 (2015). DOI 10.2138/rmg.2015.80.07

142. Stipp, S.L.S., Eggleston, C.M., Nielsen, B.S.: Calcite surface observed at microtopographic and molecular scales with atomic force microscopy (AFM). Geochimica et Cosmochimica Acta 58, 3023-3033 (1994). 14 
143. Szymczak, P., Ladd, A.: Microscopic simulations of fracture dissolution. Geophysical research letters 31(23), 1-4 (2004). DOI 10.1029/2004GL021297

144. Szymczak, P., Ladd, A.: Wormhole formation in dissolving fractures. Journal of Geophysical Research: Solid Earth 114(B6), 1-22 (2009)

145. Tartakovsky, A.M., Meakin, P., Scheibe, T.D., West, R.M.E.: Simulations of reactive transport and precipitation with smoothed particle hydrodynamics. Journal of Computational Physics 222(2), 654-672 (2007)

146. Tartakovsky, A.M., Meakin, P., Scheibe, T.D., Wood, B.D.: A smoothed particle hydrodynamics model for reactive transport and mineral precipitation in porous and fractured porous media. Water Resources Research 43 (2007). DOI 10.1029/2005wr004770

147. Tournassat, C., Steefel, C.I.: Ionic transport in nano-porous clays with consideration of electrostatic effects. In: C.I. Steefel, S. Emmanuel, L.M. Anovitz (eds.) Pore-Scale Geochemical Processes, Reviews in Mineralogy \&3 Geochemistry, vol. 80, pp. 287-329. Mineralogical Soc Amer (2015)

148. Vacondio, R., Altomare, C., Leffe, M.D., Hu, X., Touzé, D.L., Lind, S., Marongiu, J.C., Marrone, S., Rogers, B.D., Souto-Iglesias, A.: Grand challenges for smoothed particle hydrodynamics numerical schemes. Computational Particle Mechanics (2020). DOI 10.1007/s40571-020-00354-1

149. van Noorden, T.L.: Crystal precipitation and dissolution in a porous medium: Effective equations and numerical experiments. Multiscale Modeling \& Simulation 7, 1220-1236 (2009). DOI 10.1137/080722096

150. Verberg, R., Ladd, A.: Simulation of chemical erosion in rough fractures. Physical Review E 65(5), 056311 (2002)

151. Voltolini, M., Ajo-Franklin, J.: The effect of CO2-induced dissolution on flow properties in indiana limestone: An in situ synchrotron x-ray micro-tomography study. International Journal of Greenhouse Gas Control 82, 38-47 (2019). DOI https://doi.org/10.1016/j. ijggc.2018.12.013

152. Wan, J., Kim, Y., Tokunaga, T.K.: Contact angle measurement ambiguity in supercritical co2-water-mineral systems: Mica as an example. International Journal of Greenhouse Gas Control 31, 128-137 (2014)

153. Wen, H., Li, L.: An upscaled rate law for magnesite dissolution in heterogeneous porous media. Geochimica et Cosmochimica Acta 210, 289 - 305 (2017). DOI https://doi. org/10.1016/j.gca.2017.04.019. URL http://www.sciencedirect.com/science/article/ $\mathrm{pii} / \mathrm{S} 001670371730234 \mathrm{X}$

154. Whitaker, S.: The method of volume averaging, theory and applications of transport in porous media, Ther, vol. 13. Dorderecht: Kluwer Academic (1999)

155. Xu, Z., Huang, H., Li, X., Meakin, P.: Phase field and level set methods for modeling solute precipitation and/or dissolution. Computer Physics Communications 183(1), 15$19(2012)$

156. Xu, Z., Meakin, P.: Phase-field modeling of solute precipitation and dissolution. The Journal of chemical physics 129(1), 014705 (2008)

157. Xu, Z., Meakin, P.: Phase-field modeling of two-dimensional solute precipitation/dissolution: Solid fingers and diffusion-limited precipitation. The Journal of chemical physics 134(4), 044137 (2011)

158. Xuan, C., Mu, W.: Dissolution kinetics of arbitrarily-shaped alumina in oxide melt: An integration of phase-field modelling and real-time observation study. Journal of Alloys and Compounds 834, 155168 (2020). DOI 10.1016/j.jallcom.2020.155168

159. Yousefzadeh, M., Battiato, I.: Physics-based hybrid method for multiscale transport in porous media. Journal of Computational Physics 344, 320-338 (2017)

160. Yuan, K., Starchenko, V., Lee, S.S., De Andrade, V., Gursoy, D., Sturchio, N.C., Fenter, P.: Mapping three-dimensional dissolution rates of calcite microcrystals: Effects of surface curvature and dissolved metal ions. ACS Earth and Space Chemistry 3(5), 833-843 (2019)

161. Zhu, W., Fusseis, F., Lisabeth, H., Xing, T., Xiao, X., De Andrade, V., Karato, S.i.: Experimental evidence of reaction-induced fracturing during olivine carbonation. Geophysical Research Letters 43(18), 9535-9543 (2016). DOI 10.1002/2016gl070834

162. Zitová, B., Flusser, J.: Image registration methods: a survey. Image and Vision Computing 21(11), 977 - 1000 (2003). DOI https://doi.org/10.1016/S0262-8856(03)00137-9. URL http://www.sciencedirect.com/science/article/pii/S0262885603001379 